\title{
Hydraulic diffusivity of fault gouge zones and implications for thermal pressurization during seismic slip
}

\author{
Christopher A. J. Wibberley \\ Department of Geology and Mineralogy, Graduate School of Science, Kyoto University, Kyoto 606-8502, Japan
}

(Received February 13, 2002; Revised August 6, 2002; Accepted September 30, 2002)

\begin{abstract}
Laboratory-determined permeability and compressibility data for natural fault gouge samples from the Median Tectonic Line (MTL) are presented and used to estimate hydraulic diffusivities in fault gouge zones. Bulk compressibility varies with effective pressure in a log-linear manner. Hydraulic diffusivity decreases significantly during the first isotropic loading partly due to a plastic compaction component, but does not significantly change during elastic unloading. Hydraulic diffusivity decreases with decreasing gouge grain size and is lowest in the very fine-grained centre of the fault zone, identified as the most recent principal displacement zone of the MTL. Previous models of fluid-controlled dynamic strength evolution during seismic slip are assessed using the data. The data suggest that the most recent principal displacement zone has a characteristic hydraulic diffusion length lower than the half width of the low-permeability zone. Hence pressurized fluid is unlikely to escape into the surrounding high-permeability fault rocks over the lifetime of an earthquake slip event, suggesting that thermal pressurization is likely to occur if the rupture plane is confined to the low-permeability gouge principal displacement zone.
\end{abstract}

\section{Introduction}

Shear zone fluid pressure has been highlighted in conceptual and theoretical models for the past 30 years or so as controlling fault strength changes during earthquake slip, and hence overall stress release during the earthquake (e.g. Sibson, 1973; Lachenbruch, 1980; Hickman et al., 1995). However, there is still a great need to have data to constrain these models, especially because of the importance of such models in predicting earthquake magnitudes and reoccurrence times (e.g. Miller, 2002). One of the most important parameters in such models is hydraulic diffusivity, which is controlled by the permeability and fluid-pore compressibility of the fault zone material, and by fluid viscosity. Indeed, in theoretical studies of the thermal pressurization model of slip weakening, Lachenbruch (1980) and Mase and Smith (1987) both identified permeability as being one of the most influential and uncertain physical parameters of fault zone materials at relevant depths.

Previous laboratory works on fluid flow properties of natural fault gouges have shown that fault gouge generally has a low permeability with a significant anisotropy in permeability (e.g. Chu et al., 1981; Morrow et al., 1981, 1984; Faulkner and Rutter, 2000). Recently however, a few studies using well-defined structural context have encompassed other types of fault rocks and the general permeability structure of fault zones (Evans et al., 1997; Seront et al., 1998; Wibberley and Shimamoto, 2003). These integrated studies have shown that gouge zones forming a fault 'core' tend to have permeabilities significantly lower than surrounding

Copy right (c) The Society of Geomagnetism and Earth, Planetary and Space Sciences (SGEPSS); The Seismological Society of Japan; The Volcanological Society of Japan; The Geodetic Society of Japan; The Japanese Society for Planetary Sciences. 'damage zone' fault rocks, notably cataclasites and zones of fractured protolith, in fault zones modelled by Caine et al. (1996) as being a dual conduit/barrier system. This simple model is consistent with observations on internal structure of the Nojima fault zone (e.g. Ohtani et al., 2001; Kobayashi et al., 2001), laboratory-determined low permeability of Nojima gouge cores (Lockner et al., 2000; Mizoguchi et al., 2000) and high fault-parallel permeability determined from in situ water injection experiments (Tadokoro et al., 2001) in which water was probably migrating in the fracture damage zone. However, assessing the hydrodynamic behaviour of the core zone during rapid slip requires more detailed examination of the permeability and poro-elastic properties and their variations with effective pressure. This paper aims to present such an examination for the first time, with the additional constraint that the samples were collected from in and around a narrow principal displacement zone within a much wider core of a large fault zone (Wibberley and Shimamoto, 2003).

\section{The Median Tectonic Line Gouge Zone}

The Median Tectonic Line is Japan's largest onshore fault (Fig. 1(a)) with a history of sinistral displacement dating back to the early Cretaceous (e.g. Ichikawa, 1980). Ryoke terrain mylonites juxtaposed against Sambagawa terrain schists have yielded a variety of fault rocks at different temperatures and pressures during the deformation and exhumation history of the Median Tectonic Line (e.g. Takagi, 1986). Miocene-onwards dextral reactivation has occurred on the Median Tectonic Line, but the fault is currently active only in Shikoku and the western part of the Kii Peninsula. Excellent exposure of the fault zone near Tsukide in western Mie Prefecture (Fig. 1(b)) shows that a significant 


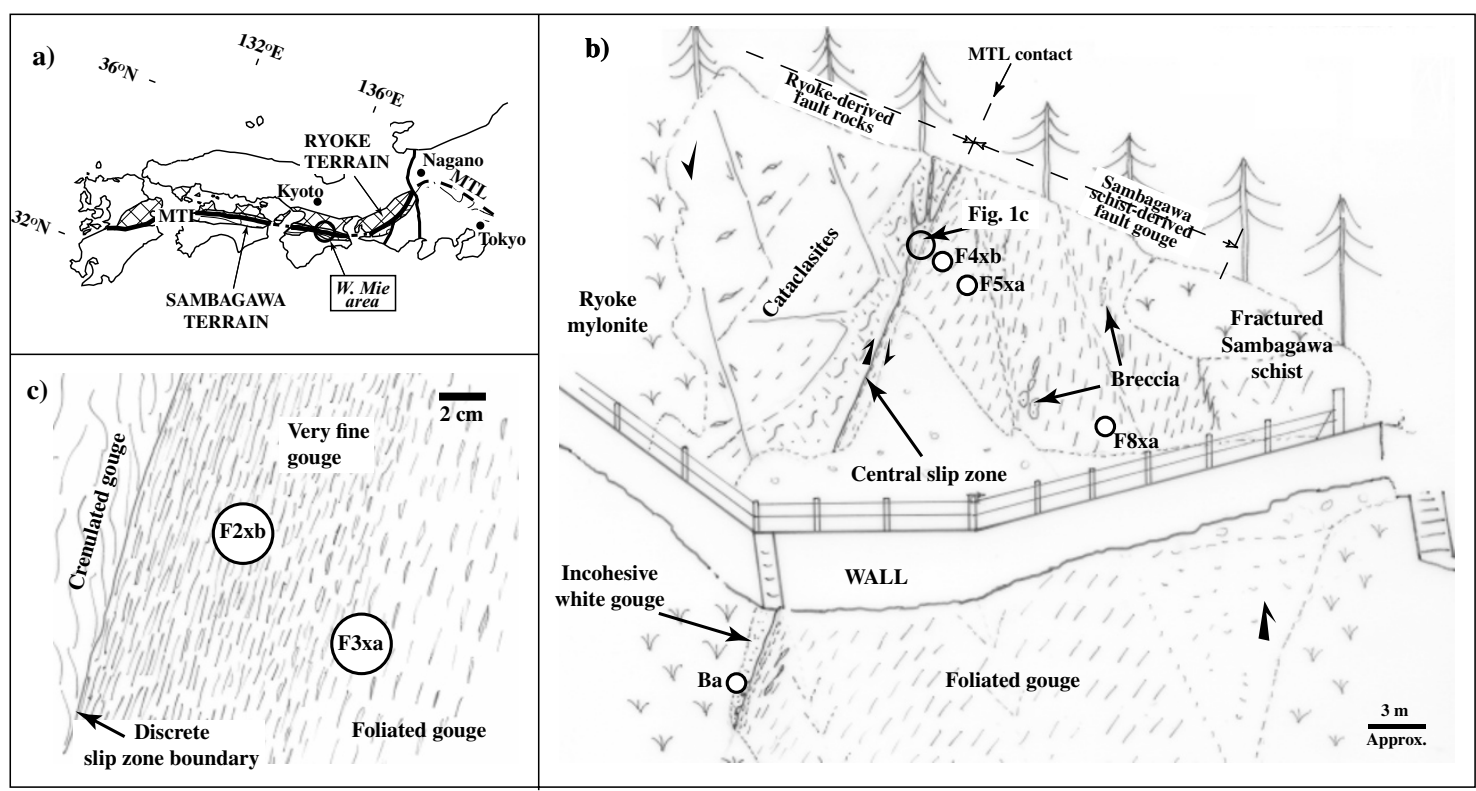

Fig. 1. Structural context of the gouge slip zone studied. (a) Regional map of the Median Tectonic Line. (b) Sketch of the upper portion of the Tsukide exposure of the Median Tectonic Line fault zone in western Mie Prefecture, showing the locations of samples. (c) Close-up sketch of the central slip zone, showing the location of samples taken.

Table 1. Details of samples used in this study for permeability measurements.

\begin{tabular}{lccc}
\hline \multicolumn{1}{c}{ Fault rock type } & $\begin{array}{c}\text { Sample } \\
\text { name }\end{array}$ & $\begin{array}{c}\text { Fault-perpendicular distance } \\
\text { from slip zone boundary }(\mathrm{m})\end{array}$ & Weight \% of grains $>250 \mu \mathrm{m}$ \\
\hline Coarse white gouge & $\mathrm{Ba}$ & -0.45 & 58.4 \\
Very fine gouge & $\mathrm{F} 2 \mathrm{xb}$ & 0.05 & 3.74 \\
Foliated gouge & $\mathrm{F} 3 \mathrm{xa}$ & 0.1 & 23.2 \\
Foliated gouge & $\mathrm{F} 4 \mathrm{xb}$ & 0.35 & 34.5 \\
Foliated gouge & $\mathrm{F} 5 \mathrm{xa}$ & 1.05 & 38.4 \\
Coarse foliated gouge & F8xa & 11.8 & 75.3 \\
\hline
\end{tabular}

portion of the fault rocks in the central 'core' zone are foliated gouges, derived from Sambagawa schist (Wibberley and Shimamoto, 2003). At the contact with Ryoke-derived fault rocks, a $10 \mathrm{~cm}$ wide dextral slickenside-bounded planar zone of intensely sheared gouge termed 'central slip zone' (Figs. 1(b), (c)) cross-cuts all other structures, and is interpreted to represent the principal displacement zone of the most recent, possibly seismogenic, deformation.

Previous work on the overall permeability structure of the fault zone from laboratory room temperature experiments (Wibberley and Shimamoto, 2003) has shown that gouges from the central slip zone have the lowest permeabilities of all the fault rocks. For the gouges, grain size correlates well with permeability, both of which decrease inwards systematically from the edge of the fault zone to the central slip zone (Table 1). All these gouges consist of a phyllosilicate matrixsupported quartz clast fabric, with both clast size and proportion varying considerably (Wibberley and Shimamoto, 2003). The central slip zone gouges contain quartz clasts which are both very small and of low proportion relative to the clay matrix. The coarse foliated gouge has a high proportion of quartz clasts which are also much larger, al- most providing a clast-supported framework. XRD work determined the matrix composition as being dominated by illite/muscovite, and no wetting clays were detected. The work described in this paper has determined not only permeability data of the gouges at and around the central slip zone in more detail than Wibberley and Shimamoto (2003), but fluid storage and compressibility data as well, in order to estimate likely hydraulic diffusivities of the gouges. The gouge samples used in this study (Table 1) are located in the outcrop sketches (Figs. 1(b), (c)), with the 'F-series' being black foliated gouges and very fine-grained slip zone gouge (F2 being the finest in the centre of the slip zone and F8 being the coarsest towards the edge of the fault zone), and coarse white gouge $(\mathrm{Ba})$.

\section{Experimental Methodology}

The experiments described in this paper were performed using the high pressure deformation and fluid flow gas apparatus at Kyoto University. Samples were collected parallel to gouge foliation by hammering $25 \mathrm{~mm}$ internal diameter steel tubes (thinned to a wall thickness of about $0.5 \mathrm{~mm}$ ) into the gouge outcrop and directly transferring them to polyolefin 
jackets stoppered with porous end pieces. The samples were oven dried at $80^{\circ} \mathrm{C}$ to eliminate pore water, without removing structured water adsorbed onto clay mineral surfaces. After removing the stoppers, each of the samples was then placed between perforated brass spacers and further jacketed with the end pistons before being inserted into the pressure vessel of the gas rig.

Nitrogen gas was used both as a confining medium and a pore fluid. The samples were subjected to initial confining and pore fluid pressures of $20 \mathrm{MPa}$. The confining pressure $(P c)$ was then increased in steps up to a peak pressure of 200 $\mathrm{MPa}$, and decreased in steps back to $20 \mathrm{MPa}$. During each confining pressure step, the change in pore volume of the sample was measured with a volumometer under 'drained' conditions. By assuming that the pore volume change $(\Delta V p)$ in the sample represented the entire volume change (i.e. that the mineral phases are relatively incompressible in comparison to the pores), pore volume change data were used to calculate total sample volumetric strain. At the beginning and end of each confining pressure step, the piston position at which incipient loading of the sample occurs ('hitpoint') was measured, and the difference taken as an estimate of the change in sample length during each confining pressure step. Axial strains were calculated from the piston displacement data. After each confining pressure step, permeability $(k)$ and sample storage capacity $\left(\beta_{c}\right)$ measurements were made using the oscillating pore pressure technique (Kranz et al., 1990; Fischer and Paterson, 1992). In this way, a set of data was obtained for a complete confining pressure cycle for each sample. For the higher permeability samples (samples Ba, F8 and F5) some additional measurements were carried out at a pore pressure $(P p)$ of $30 \mathrm{MPa}$. Sample bulk framework compressibility $\left(\beta_{b}\right)$ during each confining pressure step was calculated by finding the volume change per unit confining pressure increase, and dividing this by the sample volume at the start of the confining pressure step. This method only gives an 'average' compressibility over the $P c$ range of the step, which can be assumed to represent the compressibility at the median $P c$ of the step (Fig. 2). Such compressibility data, not presented later, tend to show a loglinear relationship with $P c$. In order to obtain compressibility values relating to the same confining pressure conditions as the oscillating pore pressure measurements, it was necessary to perform an extrapolation between two median compressibility values (e.g. extrapolating between $\beta_{b} A$ and $\beta_{b} B$ to obtain $\beta_{b} 2$ in Fig. 2). Note that this extrapolation method means that no compressibility values can be calculated for the first or last confining pressure levels reached in a series of increasing $P c$ or decreasing $P c$ tests (e.g. at Pc1 and Pc4 in Fig. 2).

The basic data obtained using the oscillating pore pressure technique on the fault gouge samples in this study are listed in Tables 2-7. A sinusoidal oscillation of the upstream pore pressure generates a downstream oscillation, out-of-phase, and of smaller amplitude but identical frequency. The ratio, $r$, of downstream-to-upstream amplitudes, and the phase lag, $\phi$, are used to calulcate two dimensionless parameters $\psi$ and $\gamma$ as described in Kranz et al. (1990) and Fischer (1992). From these two dimensionless parameters, the permeability, $k$, and sample storage capacity, $\beta_{c}$, can be eas-

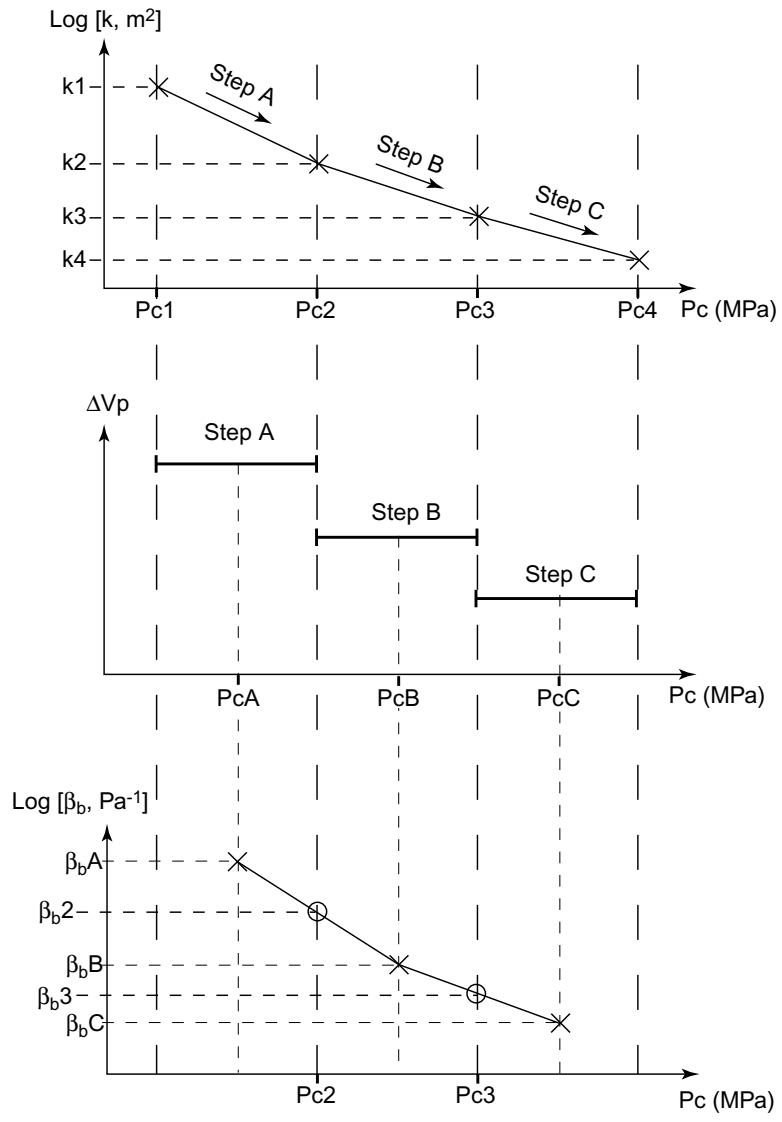

Fig. 2. Illustration of the method used for extrapolating compressibility data measured across intervals of confining pressure steps to equivalent compressibilities at the pressures at the end of the step. Compressibility values determined over finite intervals are assumed to be representative of the compressibility at the mid-point of the interval, i.e. at the median pressure, $\left(\mathrm{Pc}_{\text {start }}+\mathrm{Pc}_{\text {final }}\right) / 2$. Compressibilities at the end of pressure steps are estimated by extrapolating between the two adjacent median compressibilities.

ily calculated. Two ways of assessing the experimental errors in permeability and storage capacity measured with this method are by estimating the error in the measurements of $r$ and $\phi$, which depend largely on the output sensitivities of the measurement devices, and by statistical variation of repeated oscillation experiment data. In this study, the latter method is used. The lowest permeability measureable depends upon many variables including sample dimensions, downstream reservoir volume, the equilibrium pore pressure, the oscillation frequency and the sensitivity and signal-tonoise ratio of the downstream pore pressure oscillation measurement. The minimum permeability in this study with a minimum oscillating frequency of $0.001 \mathrm{~Hz}$ was approximately $3 \times 10^{-21} \mathrm{~m}^{2}$, but could be lowered if higher pore pressure or a lower downstream reservoir volume were used. Measurements approaching this value are prone to poorer reproducibility than others, hence have higher statistical errors. The maximum permeability measureable was about $3 \times 10^{-14} \mathrm{~m}^{2}$, using an oscillating frequency of up to $5 \mathrm{~Hz}$, but with many of the higher-frequency oscillation experiments the measured phase lag was smaller than mathematically required to yield the dimensionless parameters $\psi$ and $\gamma$. Fortunately, permeability is a function of $\psi^{2} \gamma$ which can 
Table 2. Data from the oscillating pore pressure experiments for sample Ba.

\begin{tabular}{|c|c|c|c|c|c|c|c|c|}
\hline Exp. No. & $\mathrm{Pc}(\mathrm{MPa})$ & Osc. Freq & $r$ & $\phi(\mathrm{rad})$ & $\psi$ & $\gamma$ & $\log \left(k, \mathrm{~m}^{2}\right)$ & $\log \left(\beta_{c}, \mathrm{~Pa}^{-1}\right)$ \\
\hline \multirow[t]{4}{*}{$267-01$} & 31.6 & 2 & 0.9147 & 0.283 & 0.470 & - & -14.050 & - \\
\hline & & 3 & 0.8999 & 0.377 & 0.492 & - & -13.914 & - \\
\hline & & 4 & 0.947 & 0.377 & 0.428 & 0.56 & -13.415 & -7.225 \\
\hline & & 5 & 0.889 & 0.942 & 0.507 & - & -13.718 & - \\
\hline \multirow[t]{4}{*}{$267-02$} & 50 & 2 & 0.699 & 0.817 & 0.248 & 8.01 & -14.399 & -8.382 \\
\hline & & 3 & 0.5756 & 0.942 & 0.843 & - & -14.382 & - \\
\hline & & 4 & 0.5054 & 1.131 & 0.535 & 2.64 & -14.282 & -7.899 \\
\hline & & 5 & 0.4859 & 1.571 & 0.948 & - & -14.262 & - \\
\hline \multirow[t]{4}{*}{$267-03$} & 72 & 1 & 0.3996 & 1.037 & 1.071 & - & -15.067 & - \\
\hline & & 2 & 0.2623 & 1.414 & 0.579 & 5.13 & -14.942 & -8.188 \\
\hline & & 3 & 0.1932 & 1.508 & 0.637 & 5.89 & -14.909 & -8.248 \\
\hline & & 4 & 0.1798 & 1.759 & 1.100 & 1.86 & -14.756 & -7.747 \\
\hline \multirow[t]{4}{*}{$267-04$} & 100.3 & 0.75 & 0.1558 & 1.367 & 1.780 & - & -15.633 & - \\
\hline & & 1 & 0.1253 & 1.461 & 0.217 & 83.69 & -15.603 & -9.401 \\
\hline & & 1.5 & 0.09305 & 1.461 & 2.313 & - & -15.559 & - \\
\hline & & 2 & 0.07518 & 1.822 & 1.007 & 6.07 & -15.495 & -8.261 \\
\hline \multirow[t]{3}{*}{$267-05$} & 125.4 & 0.5 & 0.08529 & 1.508 & 0.260 & 85.78 & -16.072 & -9.411 \\
\hline & & 0.75 & 0.0625 & 1.673 & 0.707 & 15.54 & -16.022 & -8.670 \\
\hline & & 1 & 0.05339 & 1.759 & 0.860 & 12.18 & -15.962 & -8.564 \\
\hline \multirow[t]{3}{*}{$267-06$} & 150.3 & 0.2 & 0.08778 & 1.433 & 2.382 & - & -16.363 & - \\
\hline & & 0.3 & 0.05899 & 1.508 & 2.909 & - & -16.457 & - \\
\hline & & 0.5 & 0.03774 & 1.696 & 0.703 & 26.31 & -16.422 & -8.898 \\
\hline \multirow[t]{3}{*}{$267-07$} & 173.6 & 0.2 & 0.04316 & 1.634 & 0.565 & 35.78 & -16.764 & -9.032 \\
\hline & & 0.25 & 0.03463 & 1.696 & 0.696 & 29.29 & -16.761 & -8.945 \\
\hline & & 0.3 & 0.03047 & 1.810 & 0.905 & 19.40 & -16.731 & -8.766 \\
\hline \multirow[t]{3}{*}{$267-08$} & 199.8 & 0.2 & 0.01852 & 1.810 & 0.883 & 33.84 & -17.127 & -9.007 \\
\hline & & 0.25 & 0.01564 & 1.759 & 0.785 & 51.10 & -17.107 & -9.186 \\
\hline & & 0.3 & 0.01364 & 2.073 & 1.262 & 21.50 & -17.065 & -8.811 \\
\hline \multirow[t]{4}{*}{ 267-09 } & 197.9 & 0.2 & 0.02987 & 1.659 & 0.596 & 46.65 & -17.200 & -9.422 \\
\hline & $P p=$ & 0.25 & 0.02449 & 1.759 & 0.803 & 31.05 & -17.185 & -9.245 \\
\hline & $30 \mathrm{MPa}$ & 0.3 & 0.01995 & 1.775 & 0.823 & 36.25 & -17.195 & -9.312 \\
\hline & & 0.5 & 0.0109 & 1.885 & 0.993 & 45.19 & -17.232 & -9.408 \\
\hline \multirow[t]{3}{*}{$267-10$} & 197.5 & 0.2 & 0.02004 & 1.810 & 0.886 & 31.04 & -17.093 & -8.970 \\
\hline & & 0.25 & 0.01719 & 1.822 & 0.902 & 34.89 & -17.062 & -9.021 \\
\hline & & 0.3 & 0.01273 & 1.885 & 0.996 & 38.39 & -17.111 & -9.062 \\
\hline \multirow[t]{3}{*}{$267-11$} & 187.5 & 0.2 & 0.02145 & 1.810 & 0.888 & 28.80 & -17.062 & -8.937 \\
\hline & & 0.25 & 0.01474 & 1.885 & 1.000 & 32.87 & -17.126 & -8.995 \\
\hline & & 0.3 & 0.01332 & 1.810 & 0.873 & 48.27 & -17.096 & -9.162 \\
\hline \multirow[t]{3}{*}{$267-12$} & 198.3 & 0.2 & 0.01999 & 1.759 & 0.794 & 39.01 & -17.097 & -9.069 \\
\hline & & 0.25 & 0.01645 & 1.759 & 0.787 & 48.36 & -17.086 & -9.163 \\
\hline & & 0.3 & 0.01333 & 1.810 & 0.874 & 48.16 & -17.096 & -9.161 \\
\hline \multirow[t]{3}{*}{$267-13$} & 150 & 0.2 & 0.02255 & 1.759 & 0.799 & 34.08 & -17.044 & -9.011 \\
\hline & & 0.25 & 0.01648 & 1.759 & 0.787 & 48.26 & -17.085 & -9.162 \\
\hline & & 0.3 & 0.01471 & 1.659 & 0.556 & 109.50 & -17.060 & -9.517 \\
\hline \multirow[t]{4}{*}{$267-14$} & 150.4 & 0.2 & 0.03162 & 1.634 & 0.533 & 55.14 & -17.176 & -9.494 \\
\hline & $P p=$ & 0.25 & 0.02576 & 1.634 & 0.516 & 72.35 & -17.169 & -9.612 \\
\hline & $30 \mathrm{MPa}$ & 0.3 & 0.02109 & 1.810 & 0.888 & 29.34 & -17.169 & -9.220 \\
\hline & & 0.5 & 0.0131 & 1.822 & 0.895 & 46.69 & -17.156 & -9.422 \\
\hline \multirow[t]{3}{*}{$267-15$} & 150.5 & 0.2 & 0.02182 & 1.810 & 0.889 & 28.26 & -17.055 & -8.929 \\
\hline & & 0.25 & 0.017 & 1.634 & 0.490 & 122.10 & -17.076 & -9.565 \\
\hline & & 0.3 & 0.01599 & 1.810 & 0.878 & 39.68 & -17.016 & -9.077 \\
\hline
\end{tabular}


Table 2. (continued).

\begin{tabular}{|c|c|c|c|c|c|c|c|c|}
\hline Exp. No. & Pc (MPa) & Osc. Freq & $r$ & $\phi(\mathrm{rad})$ & $\psi$ & $\gamma$ & $\log \left(k, \mathrm{~m}^{2}\right)$ & $\log \left(\beta_{c}, \mathrm{~Pa}^{-1}\right)$ \\
\hline \multirow[t]{3}{*}{$267-16$} & 140.6 & 0.2 & 0.02098 & 1.659 & 0.573 & 72.16 & -17.081 & -9.336 \\
\hline & & 0.25 & 0.01759 & 1.822 & 0.903 & 34.03 & -17.052 & -9.010 \\
\hline & & 0.3 & 0.01503 & 1.810 & 0.876 & 42.42 & -17.043 & -9.106 \\
\hline \multirow[t]{3}{*}{$267-17$} & 150.3 & 0.2 & 0.0212 & 1.659 & 0.573 & 71.26 & -17.075 & -9.331 \\
\hline & & 0.25 & 0.01776 & 1.759 & 0.789 & 44.46 & -17.051 & -9.126 \\
\hline & & 0.3 & 0.015347 & 1.659 & 0.557 & 104.30 & -17.040 & -9.496 \\
\hline \multirow[t]{4}{*}{$267-18$} & 100.4 & 0.2 & 0.02832 & 1.684 & 0.653 & 40.87 & -16.947 & -9.089 \\
\hline & & 0.25 & 0.02268 & 1.696 & 0.669 & 48.72 & -16.948 & -9.166 \\
\hline & & 0.3 & 0.01781 & 1.772 & 0.813 & 41.69 & -16.970 & -9.098 \\
\hline & & 0.5 & 0.01112 & 2.199 & 1.412 & 20.50 & -16.919 & -8.790 \\
\hline \multirow[t]{4}{*}{$267-19$} & 91.2 & 0.2 & 0.03015 & 1.659 & 0.597 & 46.10 & -16.922 & -9.142 \\
\hline & & 0.25 & 0.02498 & 1.634 & 0.514 & 75.29 & -16.908 & -9.355 \\
\hline & & 0.3 & 0.02015 & 1.810 & 0.886 & 30.85 & -16.914 & -8.967 \\
\hline & & 0.5 & 0.01264 & 1.885 & 0.996 & 38.68 & -16.892 & -9.066 \\
\hline \multirow[t]{4}{*}{$267-20$} & 100.9 & 0.2 & 0.02913 & 1.608 & 0.448 & 84.97 & -16.938 & -9.407 \\
\hline & & 0.25 & 0.0229 & 1.696 & 0.669 & 48.18 & -16.943 & -9.161 \\
\hline & & 0.3 & 0.0197 & 1.810 & 0.885 & 31.63 & -16.924 & -8.978 \\
\hline & & 0.5 & 0.01293 & 2.011 & 1.178 & 26.41 & -16.872 & -8.900 \\
\hline \multirow[t]{4}{*}{$267-21$} & 100.8 & 0.2 & 0.04387 & 1.583 & 0.412 & 66.68 & -17.035 & -9.577 \\
\hline & $P p=$ & 0.25 & 0.03513 & 1.602 & 0.447 & 70.65 & -17.034 & -9.602 \\
\hline & $30 \mathrm{MPa}$ & 0.3 & 0.02935 & 1.640 & 0.545 & 56.99 & -17.033 & -9.508 \\
\hline & & 0.5 & 0.01742 & 1.822 & 0.903 & 34.39 & -17.031 & -9.289 \\
\hline \multirow[t]{4}{*}{$267-22$} & 100.8 & 0.2 & 0.02924 & 1.608 & 0.449 & 84.50 & -16.937 & -9.405 \\
\hline & & 0.25 & 0.02283 & 1.696 & 0.669 & 48.35 & -16.944 & -9.162 \\
\hline & & 0.3 & 0.0181 & 1.810 & 0.882 & 34.70 & -16.961 & -9.018 \\
\hline & & 0.5 & 0.01139 & 2.011 & 1.176 & 30.17 & -16.928 & -8.957 \\
\hline \multirow[t]{4}{*}{$267-23$} & 50.2 & 0.25 & 0.05109 & 1.539 & 0.243 & 164.89 & -16.598 & -9.695 \\
\hline & & 0.3 & 0.04331 & 1.621 & 0.531 & 40.48 & -16.587 & -9.085 \\
\hline & & 0.5 & 0.02703 & 1.634 & 0.520 & 67.94 & -16.572 & -9.310 \\
\hline & & 0.75 & 0.0175 & 2.168 & 1.385 & 13.48 & -16.545 & -8.608 \\
\hline \multirow[t]{4}{*}{$267-24$} & 50.6 & 0.25 & 0.1061 & 1.508 & 0.362 & 35.41 & -16.551 & -9.302 \\
\hline & $P p=$ & 0.3 & 0.08596 & 1.536 & 0.394 & 36.97 & -16.564 & -9.321 \\
\hline & $30 \mathrm{MPa}$ & 0.5 & 0.05639 & 1.602 & 0.515 & 33.02 & -16.525 & -9.272 \\
\hline & & 0.75 & 0.03907 & 1.696 & 0.706 & 25.18 & -16.505 & -9.154 \\
\hline \multirow[t]{4}{*}{$267-25$} & 50.8 & 0.25 & 0.05905 & 1.539 & 0.288 & 101.31 & -16.534 & -9.484 \\
\hline & & 0.3 & 0.04915 & 1.659 & 0.644 & 24.07 & -16.529 & -8.859 \\
\hline & & 0.5 & 0.03222 & 1.728 & 0.757 & 26.54 & -16.490 & -8.902 \\
\hline & & 0.75 & 0.02075 & 1.791 & 0.854 & 32.34 & -16.505 & -8.988 \\
\hline \multirow[t]{4}{*}{$267-26$} & 40.6 & 0.25 & 0.07545 & 1.492 & 2.571 & - & -16.429 & - \\
\hline & & 0.3 & 0.06295 & 1.583 & 0.477 & 34.42 & -16.424 & -9.015 \\
\hline & & 0.5 & 0.04142 & 1.665 & 0.640 & 28.98 & -16.383 & -8.940 \\
\hline & & 0.75 & 0.02414 & 1.885 & 1.016 & 19.27 & -16.431 & -8.763 \\
\hline \multirow[t]{4}{*}{$267-27$} & 50.6 & 0.25 & 0.06105 & 1.539 & 0.299 & 91.31 & -16.521 & -9.439 \\
\hline & & 0.3 & 0.05138 & 1.583 & 0.439 & 50.08 & -16.515 & -9.178 \\
\hline & & 0.5 & 0.03178 & 1.759 & 0.817 & 22.98 & -16.494 & -8.839 \\
\hline & & 0.75 & 0.01973 & 1.885 & 1.008 & 24.03 & -16.520 & -8.859 \\
\hline \multirow[t]{4}{*}{$267-28$} & 30 & 0.3 & 0.1542 & 1.433 & 0.223 & 63.88 & -16.032 & -9.283 \\
\hline & & 0.5 & 0.09953 & 1.524 & 0.398 & 31.17 & -16.002 & -8.972 \\
\hline & & 0.75 & 0.07079 & 1.555 & 0.408 & 42.05 & -15.977 & -9.102 \\
\hline & & 1 & 0.05185 & 1.696 & 0.734 & 17.42 & -15.980 & -8.719 \\
\hline
\end{tabular}


Table 3. Data from the oscillating pore pressure experiments for sample F2xb.

\begin{tabular}{|c|c|c|c|c|c|c|c|c|}
\hline Exp. No. & $\mathrm{Pc}(\mathrm{MPa})$ & Osc. Freq & $r$ & $\phi(\mathrm{rad})$ & $\psi$ & $\gamma$ & $\log \left(k, \mathrm{~m}^{2}\right)$ & $\log \left(\beta_{c}, \mathrm{~Pa}^{-1}\right)$ \\
\hline \multirow[t]{3}{*}{$256-01$} & 30.2 & 2 & 0.1176 & 1.759 & 0.981 & 3.97 & -15.107 & -8.246 \\
\hline & & 2.5 & 0.09426 & 1.885 & 1.138 & 3.61 & -15.097 & -8.204 \\
\hline & & 3 & 0.08918 & 1.696 & 0.813 & 8.04 & -15.074 & -8.553 \\
\hline \multirow[t]{3}{*}{$256-02$} & 49.9 & 0.1 & 0.05422 & 1.860 & 1.029 & 8.15 & -16.762 & -8.558 \\
\hline & & 0.2 & 0.02322 & 2.011 & 1.195 & 14.11 & -16.829 & -8.797 \\
\hline & & 0.5 & 0.006587 & 2.702 & 1.946 & 15.28 & -16.889 & -8.831 \\
\hline \multirow[t]{2}{*}{$256-03$} & 74.5 & 0.03 & 0.008829 & 3.393 & 2.656 & 4.05 & -17.805 & -8.255 \\
\hline & & 0.05 & 0.00451 & 2.865 & 2.105 & 17.77 & -18.023 & -8.897 \\
\hline \multirow[t]{5}{*}{$256-04$} & 98.1 & 0.01 & 0.003455 & 2.702 & 1.938 & 29.68 & -18.873 & -9.120 \\
\hline & & 0.01 & 0.00299 & 3.016 & 2.251 & 21.84 & -18.870 & -8.986 \\
\hline & & 0.01 & 0.002724 & 2.626 & 1.860 & 42.33 & -18.991 & -9.274 \\
\hline & & 0.01 & 0.003189 & 3.192 & 2.427 & 15.95 & -18.799 & -8.850 \\
\hline & & 0.01 & 0.003256 & 2.890 & 2.127 & 23.95 & -18.860 & -9.026 \\
\hline \multirow[t]{5}{*}{$256-05$} & 124.9 & 0.003 & 0.002105 & 3.121 & 2.352 & 26.97 & -19.522 & -9.078 \\
\hline & & 0.003 & 0.002601 & 3.091 & 2.324 & 22.65 & -19.436 & -9.002 \\
\hline & & 0.003 & 0.002477 & 2.609 & 1.842 & 47.83 & -19.559 & -9.327 \\
\hline & & 0.003 & 0.002663 & 2.955 & 2.189 & 26.82 & -19.458 & -9.076 \\
\hline & & 0.003 & 0.002601 & 3.147 & 2.385 & 20.79 & -19.421 & -8.965 \\
\hline \multirow[t]{4}{*}{$256-06$} & 150.4 & 0.001 & 0.002793 & 3.091 & 2.325 & 21.06 & -19.882 & -8.971 \\
\hline & & 0.001 & 0.003296 & 3.077 & 2.313 & 18.12 & -19.812 & -8.905 \\
\hline & & 0.001 & 0.003687 & 2.850 & 2.088 & 22.35 & -19.814 & -8.997 \\
\hline & & 0.001 & 0.003128 & 3.046 & 2.281 & 19.99 & -19.843 & -8.948 \\
\hline \multirow[t]{5}{*}{$256-07$} & 174 & 0.001 & 0.000705 & 3.212 & 2.437 & 71.84 & -20.456 & -9.503 \\
\hline & & 0.001 & 0.000729 & 4.509 & 3.734 & 12.29 & -20.060 & -8.737 \\
\hline & & 0.001 & 0.000428 & 3.514 & 2.734 & 78.66 & -20.595 & -9.543 \\
\hline & & 0.001 & 0.000705 & 3.197 & 2.422 & 73.34 & -20.459 & -9.512 \\
\hline & & 0.001 & 0.000719 & 4.433 & 3.657 & 13.74 & -20.090 & -8.785 \\
\hline \multirow[t]{5}{*}{$256-08$} & 200 & 0.001 & 0.000324 & 3.845 & 3.063 & 66.70 & -20.622 & -9.471 \\
\hline & & 0.001 & 0.000316 & 4.011 & 3.228 & 54.93 & -20.583 & -9.387 \\
\hline & & 0.001 & 0.000271 & 3.891 & 3.107 & 75.20 & -20.687 & -9.523 \\
\hline & & 0.001 & 0.000255 & 4.102 & 3.318 & 60.54 & -20.650 & -9.429 \\
\hline & & 0.001 & 0.000427 & 4.554 & 3.775 & 20.00 & -20.281 & -8.948 \\
\hline \multirow[t]{4}{*}{ 256-09 } & 164.5 & 0.001 & 0.000365 & 4.735 & 3.956 & 18.63 & -20.290 & -8.917 \\
\hline & & 0.001 & 0.000341 & 4.780 & 4.001 & 18.82 & -20.305 & -8.922 \\
\hline & & 0.001 & 0.000315 & 4.026 & 3.244 & 53.94 & -20.580 & -9.379 \\
\hline & & 0.001 & 0.000446 & 4.222 & 3.441 & 29.39 & -20.367 & -9.115 \\
\hline \multirow[t]{3}{*}{$256-10$} & 50.5 & 0.001 & 0.001986 & 3.121 & 2.352 & 28.61 & -20.025 & -9.104 \\
\hline & & 0.001 & 0.002207 & 2.971 & 2.039 & 40.79 & -20.055 & -9.258 \\
\hline & & 0.001 & 0.002207 & 2.789 & 2.023 & 41.20 & -20.053 & -9.262 \\
\hline \multirow[t]{4}{*}{$256-11$} & 30.4 & 0.005 & 0.001099 & 2.978 & 2.208 & 63.62 & -19.773 & -9.724 \\
\hline & & 0.005 & 0.00088 & 2.695 & 1.926 & 119.50 & -19.570 & -9.367 \\
\hline & & 0.005 & 0.001168 & 3.072 & 2.301 & 52.42 & -19.882 & -9.896 \\
\hline & & 0.005 & 0.000723 & 2.564 & 1.791 & 177.50 & -19.618 & -9.451 \\
\hline \multirow[t]{5}{*}{$256-12$} & 25.4 & 0.005 & 0.0045 & 2.601 & 1.838 & 26.36 & -19.076 & -9.068 \\
\hline & & 0.005 & 0.004583 & 2.469 & 1.701 & 31.81 & -19.091 & -9.150 \\
\hline & & 0.005 & 0.00525 & 2.827 & 2.069 & 16.05 & -18.964 & -8.853 \\
\hline & & 0.005 & 0.004917 & 2.394 & 1.620 & 33.50 & -19.071 & -9.172 \\
\hline & & 0.005 & 0.00525 & 2.865 & 2.107 & 15.19 & -18.955 & -8.829 \\
\hline
\end{tabular}


Table 4. Data from the oscillating pore pressure experiments for sample F3xa.

\begin{tabular}{|c|c|c|c|c|c|c|c|c|}
\hline Exp. No. & $\mathrm{Pc}(\mathrm{MPa})$ & Osc. Freq & $r$ & $\phi(\mathrm{rad})$ & $\psi$ & $\gamma$ & $\log \left(k, \mathrm{~m}^{2}\right)$ & $\log \left(\beta_{c}, \mathrm{~Pa}^{-1}\right)$ \\
\hline \multirow[t]{4}{*}{$238-01$} & 30.4 & 1.5 & 0.275 & 1.367 & 0.478 & 7.31 & -14.833 & -8.561 \\
\hline & & 2 & 0.2172 & 1.508 & 0.698 & 4.25 & -14.801 & -8.326 \\
\hline & & 2.5 & 0.1766 & 1.571 & 0.743 & 4.68 & -14.800 & -8.367 \\
\hline & & 3 & 0.1607 & 1.649 & 0.868 & 3.69 & -14.753 & -8.264 \\
\hline \multirow[t]{3}{*}{$238-02$} & 50 & 0.3 & 0.1136 & 1.583 & 0.621 & 10.98 & -15.936 & -8.738 \\
\hline & & 0.5 & 0.08241 & 1.948 & 1.209 & 3.63 & -15.812 & -8.257 \\
\hline & & 0.7 & 0.05556 & 2.066 & 1.323 & 4.50 & -15.837 & -8.350 \\
\hline \multirow[t]{3}{*}{$238-03$} & 74.2 & 0.1 & 0.05794 & 1.659 & 0.665 & 19.06 & -16.712 & -8.978 \\
\hline & & 0.2 & 0.02688 & 2.035 & 1.234 & 11.31 & -16.721 & -8.751 \\
\hline & & 0.3 & 0.01813 & 2.450 & 1.707 & 7.75 & -16.663 & -8.586 \\
\hline \multirow[t]{2}{*}{$238-04$} & 100.7 & 0.05 & 0.02428 & 1.973 & 1.145 & 14.81 & -17.375 & -8.867 \\
\hline & & 0.1 & 0.01113 & 2.538 & 1.787 & 11.34 & -17.345 & -8.752 \\
\hline \multirow[t]{5}{*}{$238-05$} & 126 & 0.03 & 0.01717 & 2.054 & 1.243 & 17.60 & -17.744 & -8.943 \\
\hline & & 0.03 & 0.01698 & 1.998 & 1.168 & 20.41 & -17.754 & -9.007 \\
\hline & & 0.03 & 0.01717 & 2.018 & 1.194 & 19.22 & -17.747 & -8.981 \\
\hline & & 0.03 & 0.01736 & 1.960 & 1.115 & 22.06 & -17.747 & -9.041 \\
\hline & & 0.03 & 0.01755 & 1.998 & 1.169 & 19.70 & -17.739 & -8.992 \\
\hline \multirow[t]{5}{*}{$238-06$} & 150.8 & 0.015 & 0.01444 & 1.998 & 1.164 & 24.24 & -18.126 & -9.082 \\
\hline & & 0.015 & 0.01367 & 2.093 & 1.286 & 20.55 & -18.141 & -9.010 \\
\hline & & 0.015 & 0.0135 & 2.149 & 1.355 & 18.48 & -18.141 & -8.964 \\
\hline & & 0.015 & 0.0141 & 2.018 & 1.189 & 23.69 & -18.135 & -9.072 \\
\hline & & 0.015 & 0.01435 & 1.998 & 1.164 & 24.41 & -18.129 & -9.085 \\
\hline \multirow[t]{4}{*}{$238-07$} & 174.6 & 0.01 & 0.0161 & 1.810 & 0.879 & 39.34 & -18.269 & -9.292 \\
\hline & & 0.01 & 0.01673 & 1.810 & 0.880 & 37.74 & -18.252 & -9.274 \\
\hline & & 0.01 & 0.01555 & 1.709 & 0.680 & 68.90 & -18.289 & -9.536 \\
\hline & & 0.01 & 0.01427 & 1.909 & 1.036 & 31.48 & -18.315 & -9.195 \\
\hline
\end{tabular}

be found from the approximation $\psi^{2} \gamma=0.5\left(r^{-2}-1\right)^{0.5}$ over a limited range of $\psi, \gamma$. However, storage capacity can not be determined in such cases. In Tables 2-7, where these cases occur, the $\psi^{2} \gamma$ value is shown in the $\psi$ column, and the $\gamma$ column is marked with a ' - '.

\section{Results}

Firstly, data on length and volume changes during confining pressure changes are presented in the form of strains. Length strains of the sample axes are calculated from the length changes measured using the piston hitpoint method. Figure 3(a) shows that axial strains measured in this way vary very little among the different gouge samples, from 5.2 to $6.2 \%$ shortening at $\mathrm{Pc}=200 \mathrm{MPa}$. In each case, the sample did not recover its initial length upon deconfinement, and the data in Fig. 3(a) show significant permanent shortening with less than $50 \%$ recovery from peak strain. Volumetric strains were calculated by dividing the measured pore volume changes by initial total sample volume. This is not equivalent to pore volume strain, although related, because initial porosity could not be measured. With the assumption that the compressibility of the component minerals is negligible in comparison to that of the sample as a whole, these pore volume changes can also be used to cal- culate sample bulk compressibility $\left(\beta_{b}\right)$. The volume strain data in Fig. 3(b) show a systematic trend between the amount of volume strain at any given pressure, and the location and grain size of the sample. The finest-grained gouge from the central slip zone (F2) shows the lowest volume strain whilst the coarsest gouge from close to the edge of the fault zone (F8) shows the highest volume strain. Bulk compressibilities calculated from these data (Fig. 4) show a drop of half an order of magnitude at the onset of Pc decrease, due to the fact that much of the volumetric strain during confinement is permanent, plastic strain. Compressibility data vary very little among the samples (Fig. 4) except towards the peak of the increasing Pc path where compressibility in the coarser gouges increases, probably due to the onset of intraclast fracturing (Zhu and Wong, 1997). Indeed there seems to be a correlation between the distance of the gouge sample from the central slip zone (related to clast size and proportion), and both the compressibility at high pressure and the onset of rising compressibility. This suggests that coarse gouges become increasingly susceptible to intraclast fracturing as they become closer to clast-supported framework materials at high pressure.

The axial strain can be used to calculate the theoretical isotropic volumetric strain, for comparison with the actual 
Table 5. Data from the oscillating pore pressure experiments for sample F4xb.

\begin{tabular}{|c|c|c|c|c|c|c|c|c|}
\hline Exp. No. & $\mathrm{Pc}(\mathrm{MPa})$ & Osc. Freq & $r$ & $\phi(\mathrm{rad})$ & $\psi$ & $\gamma$ & $\log \left(k, m^{2}\right)$ & $\log \left(\beta_{c}, \mathrm{~Pa}^{-1}\right)$ \\
\hline \multirow[t]{3}{*}{$237-01$} & 30.8 & 1 & 0.4784 & 1.100 & 0.290 & 10.58 & -14.688 & -8.748 \\
\hline & & 2.5 & 0.2632 & 1.335 & 0.305 & 19.38 & -14.596 & -9.011 \\
\hline & & 3 & 0.2175 & 1.508 & 0.698 & 4.24 & -14.576 & -8.351 \\
\hline \multirow[t]{3}{*}{$237-02$} & 50 & 0.3 & 0.06181 & 1.734 & 0.830 & 11.28 & -16.152 & -8.776 \\
\hline & & 0.5 & 0.04174 & 1.948 & 1.139 & 8.58 & -16.086 & -8.657 \\
\hline & & 0.7 & 0.02955 & 2.023 & 1.222 & 10.48 & -16.088 & -8.744 \\
\hline \multirow[t]{3}{*}{$237-03$} & 74.8 & 0.1 & 0.02594 & 1.986 & 1.166 & 13.30 & -16.996 & -8.848 \\
\hline & & 0.2 & 0.01114 & 2.412 & 1.652 & 13.93 & -17.017 & -8.868 \\
\hline & & 0.3 & 0.005373 & 2.714 & 1.955 & 18.53 & -17.111 & -8.992 \\
\hline \multirow[t]{2}{*}{$237-04$} & 98.5 & 0.05 & 0.01404 & 2.262 & 1.490 & 14.21 & -17.538 & -8.876 \\
\hline & & 0.1 & 0.006345 & 2.199 & 1.404 & 36.58 & -17.596 & -9.287 \\
\hline \multirow[t]{5}{*}{$237-05$} & 125.5 & 0.03 & 0.006527 & 2.149 & 1.344 & 39.31 & -18.112 & -9.318 \\
\hline & & 0.03 & 0.006785 & 2.187 & 1.390 & 34.97 & -18.091 & -9.267 \\
\hline & & 0.03 & 0.00685 & 2.073 & 1.251 & 43.97 & -18.099 & -9.367 \\
\hline & & 0.03 & 0.006994 & 2.412 & 1.644 & 22.90 & -18.053 & -9.084 \\
\hline & & 0.03 & 0.006721 & 2.450 & 1.685 & 22.13 & -18.059 & -9.069 \\
\hline \multirow[t]{5}{*}{$237-06$} & 150.5 & 0.02 & 0.00781 & 1.909 & 1.025 & 59.10 & -18.230 & -9.495 \\
\hline & & 0.02 & 0.008014 & 1.659 & 0.537 & 215.60 & -18.231 & -10.057 \\
\hline & & 0.02 & 0.00747 & 1.759 & 0.768 & 112.20 & -18.258 & -9.774 \\
\hline & & 0.02 & 0.008149 & 1.608 & 0.371 & 445.30 & -18.225 & -10.372 \\
\hline & & 0.02 & 0.008217 & 1.810 & 0.864 & 80.25 & -18.215 & -9.628 \\
\hline \multirow[t]{5}{*}{$237-07$} & 175.3 & 0.02 & 0.001938 & 2.463 & 1.689 & 77.01 & -18.779 & -9.610 \\
\hline & & 0.02 & 0.002145 & 2.161 & 1.351 & 118.70 & -18.773 & -9.798 \\
\hline & & 0.02 & 0.002076 & 2.112 & 1.292 & 135.80 & -18.793 & -9.857 \\
\hline & & 0.02 & 0.002145 & 1.759 & 0.757 & 403.00 & -18.801 & -10.329 \\
\hline & & 0.02 & 0.002491 & 1.960 & 1.091 & 163.30 & -18.726 & -9.937 \\
\hline \multirow[t]{2}{*}{$237-08$} & 200.5 & 0.01 & 0.01301 & 1.709 & 0.674 & 83.86 & -18.319 & -9.647 \\
\hline & & 0.02 & 0.002129 & 1.810 & 0.853 & 318.80 & -18.803 & -10.227 \\
\hline
\end{tabular}

measured volumetric strain (Fig. 3(c)). The data show a reasonably strong 1:1 relationship for the coarser samples F8 and F5, but an increasingly poor correlation for samples that are progressively finer-grained and closer to the central slip zone, with sample F2 showing the biggest mismatch. The most likely reason for this is that this is due to the increasing anisotropy of compressibility with decreasing gouge grain size.

In order to examine the effect of permanent compaction on properties subsequent to compaction more closely, a further experiment on a fresh sample of foliated gouge (F3xb) was performed in which three complete cycles of confining pressure were made. Figure 5 shows that after the first pressure cycle peak, later pressure cycling has only very small to negligible permanent effects. Hence the sample can be considered to deform elastically thereafter, provided that later $P c-P p$ does not exceed this previous peak. This is also manifested in the compressibility data from this experiment (Fig. 5(c)) which show relatively consistent values for later pressure cycles along with the deconfining portion of the first pressure cycle. The consistency in values for later pressure cycles, both during increasing and decreasing $P c$, indicates elastic behaviour. The fact that compressibility is not constant means that the sample is behaving in a non-linear elastic manner. The higher compressibility values for the confining part of the first $P c$ cycle therefore reflect the additional input of plastic deformation during initial compaction. An interesting effect of hysteresis is shown (Figs. 5(a), (b)), noticed previously in fracture contact experiments (e.g. Scholz and Hickman, 1983) and evident in permeability measurements during pressure cycling (e.g. Morrow et al., 1986). Such hysteresis is reflected in anomalously low values for the first compressibility measurement in a series of increasing $P c$ or decreasing $P c$ steps.

Permeability data (Fig. 6(a)) show a large variation among the different samples, with the gouge from the central slip zone (F2) having a much lower permeability than the other samples. Of the F-series gouges, the coarsest (F8) has the highest permeability, although the coarse white gouge $(\mathrm{Ba})$ derived from Ryoke cataclasites on the other side of the fault core has an even higher permeability. The samples show 3 to 5 orders of magnitude permeability reduction as 

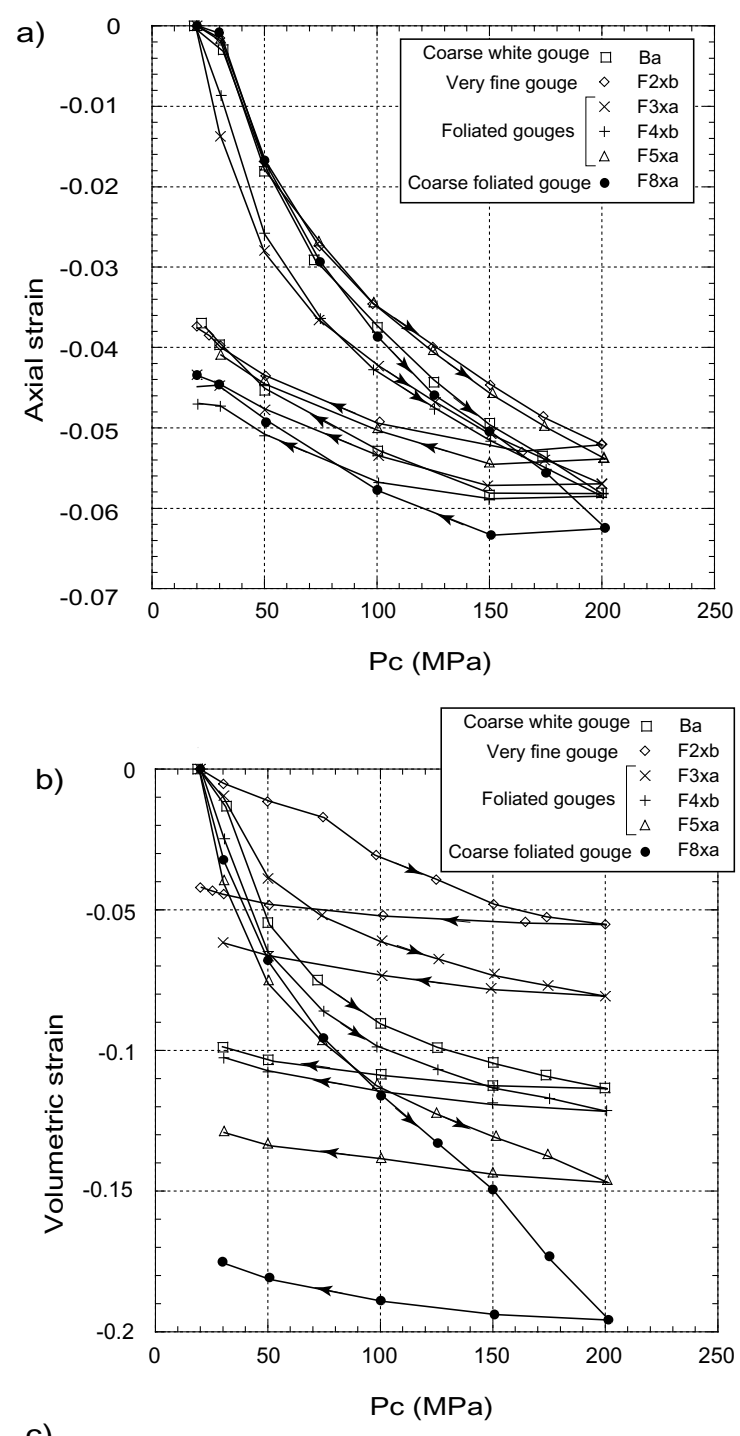

c)

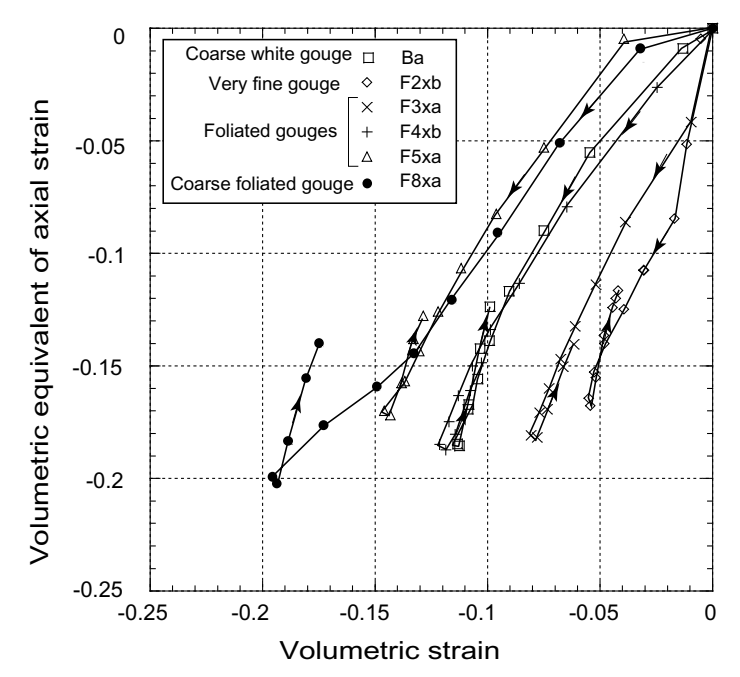

Fig. 3. The relationship between strain and confining pressure $(\mathrm{Pc})$ at a constant nitrogen gas pore pressure of $20 \mathrm{MPa}$ for the gouge samples studied. (a) Axial strain estimated from piston hitpoint data after each pressure increase. (b) Volumetric strain data measured from pore volume changes during confining pressure increases at constant pore pressure. (c) Comparison of volumetric strain calculated from the axial strain data by assuming isotropic behaviour versus the measured volumetric strain. confining pressure is increased up to $200 \mathrm{MPa}$. In each case the pressure sensitivity of permeability decreases as pressure (compaction) increases. This is most obvious for the very fine gouge (sample F2) from the central slip zone which has very high pressure sensitivities in the early stages, possibly due to the repair of cracks and foliation partings induced by artificial sample damage (Wibberley and Shimamoto, 2003).

A full description of hydrodynamic properties includes the hydraulic diffusivity $\left(D_{h}\right)$, which is related to the permeability $(k)$ and storage capacity per unit sample volume $\left(\beta_{c}\right)$ in the following way:

$$
D_{h}=\frac{k}{\eta \beta_{c}}
$$

where $\eta$ is the fluid viscosity. Storage capacity is defined as the change in the volume of pore fluid held in the system due to a unit fluid pressure change, and was measured along with permeability using nitrogen as a pore fluid. In poroelasticity theory, storage capacity is related to porosity $(n)$ and the compressibilities of the fluid $\left(\beta_{f}\right)$, mineral grain $\left(\beta_{s}\right)$ and sample bulk framework $\left(\beta_{b}\right)$ by the following relationship, assuming that an equal change in both confining and pore pressures (i.e. zero change in $P c-P p$ ) results in no porosity change:

$$
\beta_{c}=n\left(\beta_{f}-\beta_{s}\right)+\left(\beta_{b}-\beta_{s}\right) .
$$

The measured storage capacity is partly a reflection on fluid compressibility. In order to correct our measurements for the case of water storage, we firstly calculate the theoretical porosity from the measurements of storage capacity as in Eq. (2). It must be stressed that the use of Eq. (2) assumes that all constituent minerals have the same compressibility $\left(\beta_{s}\right)$, which may not strictly be true for rocks containing both quartz and phyllosilicates (Green and Wang, 1986). Published nitrogen compressibility $\left(\beta_{f}\right)$ data (at room temperature and $\left.P p=20 \mathrm{MPa}, \beta_{f}=4.32 \times 10^{-8} \mathrm{~Pa}^{-1}\right)$, a value of $1.2 \times 10^{-11} \mathrm{~Pa}^{-1}$ for compressibility of mica $\left(\beta_{s}\right)$ independent of pressure (Birch, 1966) and the bulk framework compressibility data $\left(\beta_{b}\right)$ (Fig. 3) are used. Porosities calculated in this way are in the order of $5-10 \%$ at low pressure, decreasing to $0.1-1.5 \%$ at high confining pressure. Ongoing work is being carried out to adapt the gas rig for direct porosity measurements for comparison. Storage capacity of the sample in a gouge-water system is then calculated simply from Eq. (2) with the appropriate water compressibility data and the values of $\beta_{s}$ and $\beta_{b}$ used previously. From this and the permeability data (Fig. 6(a)), hydraulic diffusivities are calculated using Eq. (1) with the room temperature viscosity of water (Fig. 6(b)). The variation in hydraulic diffusivity among the samples is similar to that of permeability because compressibility does not vary much among the samples. However, unlike the permeability, the hydraulic diffusivities remain constant or even decrease along the decreasing Pc path (Fig. 6(b)), because of the increase in measured compressibility as confining pressure decreases. The drop of half an order of magnitude in compressibility at the onset of decreasing Pc causes the calculated hydraulic diffusivity to be higher than at the end of the increasing Pc path. This is thought to be because the measured compressibility contains 
Table 6. Data from the oscillating pore pressure experiments for sample F5xa.

\begin{tabular}{|c|c|c|c|c|c|c|c|c|}
\hline Exp. No. & $\mathrm{Pc}(\mathrm{MPa})$ & Osc. Freq & $r$ & $\phi(\mathrm{rad})$ & $\psi$ & $\gamma$ & $\log \left(k, \mathrm{~m}^{2}\right)$ & $\log \left(\beta_{c}, \mathrm{~Pa}^{-1}\right)$ \\
\hline \multirow[t]{4}{*}{$236-01$} & 30.5 & 1 & 0.77766 & 0.534 & 0.636 & - & -14.452 & - \\
\hline & & 2 & 0.4 & 0.754 & 1.070 & - & -14.603 & - \\
\hline & & 3 & 0.5 & 0.942 & 0.931 & - & -14.306 & - \\
\hline & & 4 & 0.488 & 1.005 & 0.946 & - & -14.195 & - \\
\hline \multirow[t]{4}{*}{$236-02$} & 50.4 & 1 & 0.1668 & 1.508 & 0.566 & 8.87 & -15.299 & -8.627 \\
\hline & & 1.5 & 0.13 & 1.461 & 0.566 & 14.37 & -15.248 & -9.470 \\
\hline & & 2 & 0.1053 & 1.571 & 0.585 & 17.47 & -15.207 & -8.837 \\
\hline & & 3 & 0.0815 & 1.602 & 0.248 & 61.76 & -17.144 & -8.922 \\
\hline \multirow[t]{3}{*}{$236-03$} & 74.2 & 0.3 & 0.08748 & 1.527 & 0.362 & 43.00 & -16.119 & -9.313 \\
\hline & & 0.5 & 0.0511 & 1.822 & 0.964 & 10.00 & -16.114 & -8.679 \\
\hline & & 1 & 0.0297 & 2.168 & 1.406 & 7.54 & -16.019 & -8.557 \\
\hline \multirow[t]{2}{*}{$236-04$} & 98.7 & 0.1 & 0.06087 & 1.634 & 0.612 & 21.49 & -16.751 & -9.011 \\
\hline & & 0.2 & 0.03008 & 1.759 & 0.814 & 24.51 & -16.754 & -9.068 \\
\hline \multirow[t]{5}{*}{$236-05$} & 125 & 0.1 & 0.01466 & 1.810 & 0.876 & 43.57 & -17.349 & -9.120 \\
\hline & & 0.1 & 0.01654 & 1.960 & 1.115 & 23.21 & -17.372 & -9.143 \\
\hline & & 0.1 & 0.01504 & 2.061 & 1.248 & 19.96 & -17.338 & -8.979 \\
\hline & & 0.1 & 0.01429 & 1.935 & 1.075 & 29.10 & -17.305 & -9.045 \\
\hline & & 0.1 & 0.01504 & 1.935 & 1.076 & 27.57 & -17.369 & -9.318 \\
\hline \multirow[t]{5}{*}{$236-06$} & 151.5 & 0.05 & 0.009237 & 2.011 & 1.172 & 37.52 & -17.858 & -9.253 \\
\hline & & 0.05 & 0.009839 & 2.262 & 1.483 & 20.64 & -17.803 & -8.994 \\
\hline & & 0.05 & 0.01004 & 2.187 & 1.395 & 23.34 & -17.803 & -9.047 \\
\hline & & 0.05 & 0.009839 & 2.111 & 1.303 & 27.84 & -17.820 & -9.124 \\
\hline & & 0.05 & 0.01004 & 2.237 & 1.454 & 21.18 & -17.797 & -9.005 \\
\hline \multirow[t]{5}{*}{$236-07$} & 174.6 & 0.03 & 0.00696 & 2.809 & 2.055 & 12.30 & -18.083 & -8.769 \\
\hline & & 0.03 & 0.0068 & 2.394 & 1.624 & 24.01 & -18.169 & -9.060 \\
\hline & & 0.03 & 0.00736 & 2.620 & 1.864 & 15.41 & -18.097 & -8.867 \\
\hline & & 0.03 & 0.00696 & 2.507 & 1.745 & 19.49 & -18.141 & -8.969 \\
\hline & & 0.03 & 0.00752 & 2.507 & 1.746 & 17.98 & -18.107 & -8.934 \\
\hline \multirow[t]{5}{*}{$236-08$} & 200.9 & 0.02 & 0.004502 & 2.262 & 1.474 & 46.14 & -18.545 & -9.343 \\
\hline & & 0.02 & 0.004 & 2.036 & 1.197 & 83.14 & -18.620 & -9.599 \\
\hline & & 0.02 & 0.004502 & 2.312 & 1.530 & 42.16 & -18.538 & -9.304 \\
\hline & & 0.02 & 0.004589 & 2.161 & 1.356 & 54.88 & -18.548 & -9.419 \\
\hline & & 0.02 & 0.004848 & 2.388 & 1.614 & 34.34 & -18.496 & -9.215 \\
\hline \multirow[t]{5}{*}{ 236-09 } & 200.2 & 0.02 & 0.006463 & 1.960 & 1.097 & 61.93 & -18.648 & -9.703 \\
\hline & $P p=$ & 0.02 & 0.006822 & 2.136 & 1.329 & 38.53 & -18.609 & -9.497 \\
\hline & $30 \mathrm{MPa}$ & 0.02 & 0.006535 & 2.136 & 1.329 & 40.27 & -18.628 & -9.516 \\
\hline & & 0.02 & 0.006463 & 2.111 & 1.298 & 42.95 & -18.635 & -9.544 \\
\hline & & 0.02 & 0.00632 & 2.136 & 1.329 & 41.67 & -18.643 & -9.531 \\
\hline \multirow[t]{5}{*}{$236-10$} & 190.1 & 0.02 & 0.005727 & 2.337 & 1.560 & 31.55 & -18.429 & -9.135 \\
\hline & & 0.02 & 0.004772 & 1.935 & 1.059 & 90.62 & -18.551 & -9.594 \\
\hline & & 0.02 & 0.004599 & 2.237 & 1.445 & 47.30 & -18.539 & -9.311 \\
\hline & & 0.02 & 0.004165 & 2.111 & 1.294 & 67.25 & -18.596 & -9.464 \\
\hline & & 0.02 & 0.004859 & 2.413 & 1.641 & 32.86 & -18.491 & -9.153 \\
\hline \multirow[t]{5}{*}{$236-11$} & 200.4 & 0.02 & 0.004359 & 2.438 & 1.667 & 35.20 & -18.534 & -9.226 \\
\hline & & 0.02 & 0.004017 & 2.463 & 1.694 & 36.68 & -18.566 & -9.244 \\
\hline & & 0.02 & 0.004872 & 2.286 & 1.502 & 40.72 & -18.507 & -9.289 \\
\hline & & 0.02 & 0.003846 & 2.337 & 1.557 & 47.40 & -18.604 & -9.355 \\
\hline & & 0.02 & 0.004957 & 2.363 & 1.587 & 34.99 & -18.489 & -9.223 \\
\hline
\end{tabular}


Table 6. (continued).

\begin{tabular}{|c|c|c|c|c|c|c|c|c|}
\hline Exp. No. & $\mathrm{Pc}(\mathrm{MPa})$ & Osc. Freq & $r$ & $\phi(\mathrm{rad})$ & $\psi$ & $\gamma$ & $\log \left(k, \mathrm{~m}^{2}\right)$ & $\log \left(\beta_{c}, \mathrm{~Pa}^{-1}\right)$ \\
\hline \multirow[t]{5}{*}{$236-12$} & 150 & 0.02 & 0.004026 & 2.187 & 1.386 & 59.59 & -18.603 & -9.454 \\
\hline & & 0.02 & 0.00454 & 2.161 & 1.355 & 55.56 & -18.553 & -9.424 \\
\hline & & 0.02 & 0.004454 & 2.011 & 1.164 & 79.28 & -18.575 & -9.578 \\
\hline & & 0.02 & 0.004111 & 1.909 & 1.019 & 114.00 & -18.617 & -9.736 \\
\hline & & 0.02 & 0.004454 & 2.262 & 1.474 & 46.65 & -18.550 & -9.348 \\
\hline \multirow[t]{5}{*}{$236-13$} & 100.4 & 0.03 & 0.00623 & 1.885 & 0.985 & 80.67 & -18.261 & -9.586 \\
\hline & & 0.03 & 0.005902 & 2.150 & 1.345 & 43.43 & -18.263 & -9.317 \\
\hline & & 0.03 & 0.004672 & 2.112 & 1.296 & 59.75 & -18.369 & -9.455 \\
\hline & & 0.03 & 0.00582 & 1.923 & 1.043 & 76.63 & -18.289 & -9.564 \\
\hline & & 0.03 & 0.006967 & 1.960 & 1.098 & 57.33 & -18.207 & -9.438 \\
\hline \multirow[t]{5}{*}{$236-14$} & 100.8 & 0.03 & 0.008377 & 1.847 & 0.927 & 67.98 & -18.366 & -9.744 \\
\hline & $P p=$ & 0.03 & 0.008333 & 1.810 & 0.864 & 78.97 & -18.370 & -9.809 \\
\hline & $30 \mathrm{MPa}$ & 0.03 & 0.009167 & 1.923 & 1.049 & 47.98 & -18.322 & -9.592 \\
\hline & & 0.03 & 0.009123 & 2.035 & 1.205 & 35.79 & -18.316 & -9.465 \\
\hline & & 0.03 & 0.009002 & 1.885 & 0.990 & 55.17 & -18.333 & -9.653 \\
\hline \multirow[t]{5}{*}{$236-15$} & 101 & 0.03 & 0.005503 & 1.847 & 0.922 & 104.90 & -18.318 & -9.700 \\
\hline & & 0.03 & 0.005585 & 2.073 & 1.249 & 54.20 & -18.295 & -9.413 \\
\hline & & 0.03 & 0.005339 & 1.923 & 1.042 & 83.70 & -18.326 & -9.602 \\
\hline & & 0.03 & 0.004271 & 1.923 & 1.040 & 905.10 & -18.424 & -9.701 \\
\hline & & 0.03 & 0.00501 & 2.187 & 1.387 & 47.70 & -18.330 & -9.358 \\
\hline \multirow[t]{5}{*}{$236-16$} & 90.5 & 0.03 & 0.005082 & 2.112 & 1.296 & 54.84 & -18.332 & -9.418 \\
\hline & & 0.03 & 0.004836 & 2.187 & 1.387 & 49.45 & -18.346 & -9.373 \\
\hline & & 0.03 & 0.004344 & 2.450 & 1.680 & 34.64 & -18.358 & -9.219 \\
\hline & & 0.03 & 0.004426 & 2.412 & 1.639 & 36.19 & -18.356 & -9.238 \\
\hline & & 0.03 & 0.004918 & 2.375 & 1.601 & 34.55 & -18.315 & -9.218 \\
\hline \multirow[t]{5}{*}{$236-17$} & 99.9 & 0.03 & 0.004124 & 2.337 & 1.557 & 44.15 & -18.397 & -9.324 \\
\hline & & 0.03 & 0.004124 & 2.601 & 1.836 & 28.85 & -18.356 & -9.139 \\
\hline & & 0.03 & 0.004784 & 2.375 & 1.600 & 35.54 & -18.327 & -9.230 \\
\hline & & 0.03 & 0.004619 & 2.035 & 1.197 & 71.95 & -18.381 & -9.536 \\
\hline & & 0.03 & 0.004836 & 2.262 & 1.474 & 42.89 & -18.337 & -9.311 \\
\hline \multirow[t]{5}{*}{$236-18$} & 50 & 0.05 & 0.007026 & 2.231 & 1.442 & 31.02 & -17.955 & -9.171 \\
\hline & & 0.05 & 0.006707 & 2.262 & 1.477 & 30.69 & -17.972 & -9.166 \\
\hline & & 0.05 & 0.005828 & 2.011 & 1.167 & 60.26 & -18.060 & -9.459 \\
\hline & & 0.05 & 0.006547 & 2.168 & 1.367 & 37.69 & -17.994 & -9.255 \\
\hline & & 0.05 & 0.007585 & 2.356 & 1.584 & 22.87 & -17.905 & -9.038 \\
\hline \multirow[t]{5}{*}{$236-19$} & 50.3 & 0.05 & 0.0163 & 1.854 & 0.953 & 32.86 & -17.853 & -9.428 \\
\hline & $P p=$ & 0.05 & 0.01663 & 2.011 & 1.184 & 20.23 & -17.831 & -9.217 \\
\hline & $30 \mathrm{MPa}$ & 0.05 & 0.01608 & 1.932 & 1.073 & 25.91 & -17.853 & -9.325 \\
\hline & & 0.05 & 0.01552 & 1.932 & 1.072 & 26.91 & -17.868 & -9.341 \\
\hline & & 0.05 & 0.01563 & 1.932 & 1.072 & 26.70 & -17.865 & -9.338 \\
\hline \multirow[t]{5}{*}{$236-20$} & 40.1 & 0.05 & 0.01153 & 1.916 & 1.042 & 38.58 & -17.768 & -9.266 \\
\hline & & 0.05 & 0.01075 & 2.231 & 1.448 & 19.96 & -17.768 & -8.979 \\
\hline & & 0.05 & 0.01083 & 2.042 & 1.217 & 29.45 & -17.786 & -9.148 \\
\hline & & 0.05 & 0.0113 & 2.356 & 1.591 & 15.09 & -17.728 & -8.858 \\
\hline & & 0.05 & 0.01184 & 2.073 & 1.259 & 24.95 & -17.743 & -9.076 \\
\hline \multirow[t]{5}{*}{$236-21$} & 30.5 & 0.1 & 0.01464 & 2.011 & 1.181 & 23.17 & -17.354 & -9.044 \\
\hline & & 0.1 & 0.01368 & 1.979 & 1.136 & 26.98 & -17.387 & -9.110 \\
\hline & & 0.1 & 0.01329 & 2.105 & 1.301 & 20.61 & -17.388 & -8.993 \\
\hline & & 0.1 & 0.01349 & 2.042 & 1.221 & 23.40 & -17.388 & -9.048 \\
\hline & & 0.1 & 0.01291 & 2.105 & 1.300 & 21.25 & -17.400 & -9.007 \\
\hline
\end{tabular}


Table 7. Data from the oscillating pore pressure experiments for sample F8xa

\begin{tabular}{|c|c|c|c|c|c|c|c|c|}
\hline Exp. No. & $\mathrm{Pc}(\mathrm{MPa})$ & Osc. Freq & $r$ & $\phi(\mathrm{rad})$ & $\psi$ & $\gamma$ & $\log \left(k, \mathrm{~m}^{2}\right)$ & $\log \left(\beta_{c}, \mathrm{~Pa}^{-1}\right)$ \\
\hline \multirow[t]{4}{*}{$251-01$} & 30.25 & 3 & 0.8 & 0.283 & 0.612 & - & -14.154 & - \\
\hline & & 3.5 & 0.697 & 0.880 & 0.717 & - & -14.225 & - \\
\hline & & 4 & 0.6627 & 0.754 & 0.752 & - & -14.208 & - \\
\hline & & 5 & 0.6071 & 0.628 & 0.809 & - & -14.175 & - \\
\hline \multirow[t]{3}{*}{$251-02$} & 50.1 & 3 & 0.256 & 1.319 & 1.374 & - & -14.857 & - \\
\hline & & 4 & 0.2303 & 1.382 & 0.365 & 15.53 & -14.829 & -8.667 \\
\hline & & 5 & 0.1973 & 1.885 & 1.338 & 0.97 & -14.694 & -7.461 \\
\hline \multirow[t]{3}{*}{$251-03$} & 74.6 & 2 & 0.0542 & 1.759 & 0.861 & 11.94 & -15.704 & -8.553 \\
\hline & & 2.5 & 0.05322 & 1.963 & 1.180 & 6.14 & -15.592 & -8.264 \\
\hline & & 3 & 0.05739 & 1.979 & 1.209 & 5.36 & -15.475 & -8.205 \\
\hline \multirow[t]{3}{*}{$251-04$} & 100.3 & 0.5 & 0.04939 & 1.696 & 0.729 & 18.59 & -16.354 & -8.745 \\
\hline & & 0.7 & 0.03736 & 1.671 & 0.645 & 31.66 & -16.332 & -8.977 \\
\hline & & 1 & 0.02437 & 2.011 & 1.197 & 13.38 & -16.340 & -8.603 \\
\hline \multirow[t]{3}{*}{$251-05$} & 125.4 & 0.2 & 0.03867 & 1.634 & 0.553 & 41.80 & -16.863 & -9.097 \\
\hline & & 0.3 & 0.02534 & 1.810 & 0.896 & 23.92 & -16.864 & -8.855 \\
\hline & & 0.5 & 0.01672 & 2.199 & 1.421 & 13.30 & -16.788 & -8.600 \\
\hline \multirow[t]{3}{*}{$251-06$} & 149.9 & 0.1 & 0.0326 & 1.734 & 0.770 & 25.30 & -17.234 & -8.879 \\
\hline & & 0.2 & 0.0156 & 1.885 & 1.001 & 30.94 & -17.248 & -8.967 \\
\hline & & 0.3 & 0.01035 & 2.262 & 1.484 & 19.58 & -17.215 & -8.768 \\
\hline \multirow[t]{5}{*}{$251-07$} & 175 & 0.1 & 0.01543 & 1.979 & 1.139 & 23.76 & -17.547 & -8.852 \\
\hline & & 0.1 & 0.01472 & 2.011 & 1.181 & 23.03 & -17.565 & -8.838 \\
\hline & & 0.1 & 0.01517 & 1.885 & 1.001 & 31.88 & -17.562 & -8.980 \\
\hline & & 0.1 & 0.01613 & 1.759 & 0.786 & 49.40 & -17.542 & -9.170 \\
\hline & & 0.1 & 0.01613 & 2.073 & 1.266 & 18.01 & -17.518 & -8.732 \\
\hline \multirow[t]{2}{*}{$251-08$} & 200.2 & 0.1 & 0.005718 & 2.199 & 1.403 & 40.69 & -17.961 & -9.086 \\
\hline & & 0.15 & 0.00367 & 2.262 & 1.472 & 56.80 & -17.972 & -9.230 \\
\hline \multirow[t]{5}{*}{ 251-09 } & 200.5 & 0.15 & 0.006281 & 2.215 & 1.422 & 35.86 & -18.017 & -9.305 \\
\hline & $P p=$ & 0.15 & 0.007017 & 2.168 & 1.368 & 35.10 & -17.974 & -9.296 \\
\hline & $30 \mathrm{MPa}$ & 0.15 & 0.00687 & 2.121 & 1.310 & 39.54 & -17.988 & -9.348 \\
\hline & & 0.15 & 0.00633 & 2.262 & 1.477 & 32.56 & -18.008 & -9.263 \\
\hline & & 0.15 & 0.006232 & 2.215 & 1.422 & 36.15 & -18.020 & -9.309 \\
\hline \multirow[t]{2}{*}{$251-10$} & 190.5 & 0.1 & 0.006127 & 2.199 & 1.404 & 37.91 & -17.931 & -9.055 \\
\hline & & 0.15 & 0.003368 & 2.356 & 1.577 & 52.48 & -17.997 & -9.196 \\
\hline \multirow[t]{5}{*}{$251-11$} & 150.7 & 0.1 & 0.00617 & 2.199 & 1.404 & 37.64 & -17.928 & -9.052 \\
\hline & & 0.1 & 0.006655 & 2.199 & 1.404 & 34.83 & -17.894 & -9.018 \\
\hline & & 0.1 & 0.005754 & 2.231 & 1.440 & 38.07 & -17.955 & -9.057 \\
\hline & & 0.1 & 0.00617 & 2.199 & 1.404 & 37.64 & -17.928 & -9.052 \\
\hline & & 0.1 & 0.006239 & 2.325 & 1.547 & 29.53 & -17.907 & -8.946 \\
\hline \multirow[t]{5}{*}{$251-12$} & 100.1 & 0.1 & 0.008243 & 2.011 & 1.170 & 42.20 & -17.820 & -9.101 \\
\hline & & 0.1 & 0.008243 & 2.199 & 1.407 & 27.94 & -17.801 & -8.922 \\
\hline & & 0.1 & 0.008639 & 2.011 & 1.171 & 40.21 & -17.799 & -9.080 \\
\hline & & 0.1 & 0.008375 & 2.073 & 1.253 & 35.75 & -17.807 & -9.029 \\
\hline & & 0.1 & 0.008507 & 2.011 & 1.171 & 40.85 & -17.806 & -9.087 \\
\hline
\end{tabular}


Table 7. (continued).

\begin{tabular}{|c|c|c|c|c|c|c|c|c|}
\hline Exp. No. & $\mathrm{Pc}(\mathrm{MPa})$ & Osc. Freq & $r$ & $\phi(\mathrm{rad})$ & $\psi$ & $\gamma$ & $\log \left(k, \mathrm{~m}^{2}\right)$ & $\log \left(\beta_{c}, \mathrm{~Pa}^{-1}\right)$ \\
\hline \multirow[t]{5}{*}{$251-13$} & 100.5 & 0.15 & 0.008594 & 2.032 & 1.199 & 38.39 & -17.898 & -9.335 \\
\hline & $P p=$ & 0.15 & 0.00889 & 1.960 & 1.102 & 44.54 & -17.889 & -9.400 \\
\hline & $30 \mathrm{MPa}$ & 0.15 & 0.01128 & 2.111 & 1.306 & 24.14 & -17.771 & -9.134 \\
\hline & & 0.15 & 0.008756 & 2.073 & 1.254 & 34.14 & -17.886 & -9.284 \\
\hline & & 0.15 & 0.008504 & 1.998 & 1.154 & 42.10 & -17.905 & -9.375 \\
\hline \multirow[t]{5}{*}{$251-14$} & 100.7 & 0.1 & 0.007722 & 2.011 & 1.170 & 45.14 & -17.849 & -9.131 \\
\hline & & 0.1 & 0.007925 & 1.948 & 1.082 & 51.95 & -17.842 & -9.192 \\
\hline & & 0.1 & 0.008128 & 1.948 & 1.083 & 50.62 & -17.832 & -9.180 \\
\hline & & 0.1 & 0.008061 & 2.073 & 1.253 & 37.19 & -17.824 & -9.046 \\
\hline & & 0.1 & 0.008196 & 2.136 & 1.332 & 31.89 & -17.811 & -8.980 \\
\hline \multirow[t]{5}{*}{$251-15$} & 90.4 & 0.1 & 0.009636 & 2.073 & 1.255 & 30.92 & -17.745 & -8.966 \\
\hline & & 0.1 & 0.009636 & 2.262 & 1.482 & 21.09 & -17.724 & -8.800 \\
\hline & & 0.1 & 0.009332 & 2.136 & 1.333 & 27.89 & -17.753 & -8.922 \\
\hline & & 0.1 & 0.009467 & 2.073 & 1.255 & 31.49 & -17.753 & -8.974 \\
\hline & & 0.1 & 0.008723 & 2.011 & 1.171 & 39.81 & -17.795 & -9.076 \\
\hline \multirow[t]{5}{*}{$251-16$} & 100.1 & 0.1 & 0.008641 & 2.388 & 1.621 & 18.93 & -17.754 & -8.753 \\
\hline & & 0.1 & 0.007966 & 2.450 & 1.687 & 18.56 & -17.781 & -8.745 \\
\hline & & 0.1 & 0.008708 & 2.388 & 1.621 & 18.78 & -17.751 & -8.750 \\
\hline & & 0.1 & 0.008033 & 2.262 & 1.480 & 25.48 & -17.804 & -8.882 \\
\hline & & 0.1 & 0.008236 & 2.011 & 1.170 & 42.24 & -17.820 & -9.102 \\
\hline \multirow[t]{5}{*}{$251-17$} & 50.6 & 0.15 & 0.01349 & 1.744 & 0.749 & 65.19 & -17.445 & -9.290 \\
\hline & & 0.15 & 0.01391 & 1.649 & 0.527 & 128.80 & -17.435 & -9.586 \\
\hline & & 0.15 & 0.01433 & 1.744 & 0.751 & 61.05 & -17.419 & -9.262 \\
\hline & & 0.15 & 0.01475 & 1.744 & 0.752 & 59.16 & -17.406 & -9.248 \\
\hline & & 0.15 & 0.01293 & 1.885 & 0.997 & 37.76 & -17.456 & -9.053 \\
\hline \multirow[t]{2}{*}{$251-18$} & 40.2 & 0.15 & 0.0244 & 1.696 & 0.673 & 44.72 & -17.188 & -9.127 \\
\hline & & 0.2 & 0.01822 & 2.011 & 1.187 & 18.35 & -17.169 & -8.740 \\
\hline \multirow[t]{5}{*}{$251-19$} & 29.7 & 0.5 & 0.01818 & 2.011 & 1.187 & 18.39 & -16.772 & -8.741 \\
\hline & & 0.5 & 0.01818 & 2.073 & 1.269 & 15.84 & -16.765 & -8.676 \\
\hline & & 0.5 & 0.01955 & 2.136 & 1.350 & 12.77 & -16.726 & -8.582 \\
\hline & & 0.5 & 0.01909 & 2.136 & 1.350 & 13.10 & -16.737 & -8.593 \\
\hline & & 0.5 & 0.01727 & 2.011 & 1.185 & 19.43 & -16.795 & -8.764 \\
\hline
\end{tabular}

a significant plastic component as Pc increases to a peak for the first time, but behaves elastically after the peak (see discussion in Subsection 5.1). The hydraulic diffusivity values calculated for the decreasing Pc paths are therefore thought to be closer to representing true poro-elastic hydraulic diffusivities. It should be noted that the values of permeability and hydraulic diffusivity on the deconfining path will be dependent on the peak value of confining pressure experienced by the sample (Zhang and Cox, 2000; Wibberley and Shimamoto, 2003). A fault gouge subjected to a lower confining pressure (at the same pore fluid pressure) will not compact as much and therefore will exhibit higher permeabilities and hydraulic diffusivities during deconfinement than a sample subjected to a higher peak confining pressure.
5. Discussion and Implications for Slip Processes 5.1 Applicability of the measurements to hydraulic diffusivity of gouge-water systems

Two problems with applying the measurements presented in this paper to estimate the hydraulic diffusivity of fault gouge are the effect on measured gouge permeability of using nitrogen gas rather than water, and the use of the compressibility data obtained over finite strain intervals to estimate the elastic pore strain compressibility. Klinkenberg (1941) found that using different gases as pore fluids resulted in different permeabilities, whereas using different liquids did not. This 'Klinkenberg effect' was ascribed to a phenomenon of loss of continuity between pore walls and the adjacent gas molecules, unlike for liquids which are stationary at the walls. Using gas permeability will result in 

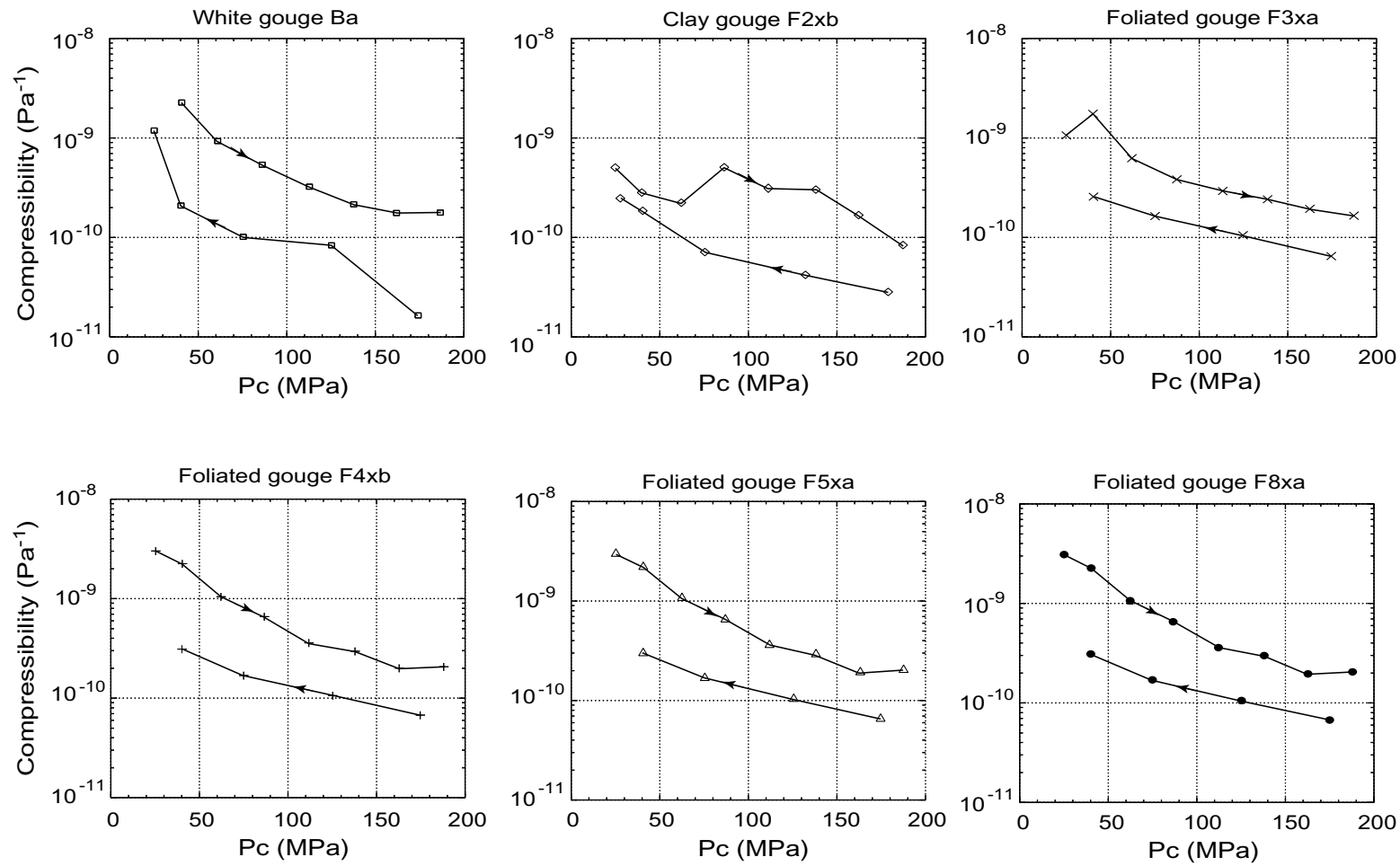

Fig. 4. Bulk framework compressibility data for each of the gouge samples studied.

higher flow rates than predicted by Darcy's law and therefore provide an overestimate of the permeability of a porous medium with water as the pore fluid. A calculation for the case of nitrogen at a pore pressure of $20 \mathrm{MPa}$ has shown that the Klinkenberg effect will lead to this overestimate being less than 10\% (Wibberley and Shimamoto, 2003). Nevertheless, comparing permeability measurements on naturally dry non-swelling clay gouges (illite/muscovite) using argon gas and water showed that water permeability is typically one order of magnitude lower than gas permeability (Faulkner and Rutter, 2000). After reviewing possible permeabilityreducing mechanisms for the case of water, Faulkner and Rutter (2000) suggested that structured water adsorbed on to the surface of the clay minerals could reduce the pore throat apertures sufficiently to cause the observed permeability reduction. The Median Tectonic Line gouge samples must have been saturated with water in situ, and drying the gouge at $80^{\circ} \mathrm{C}$ prior to the experiments was intended to eliminate the free pore water but not the adsorbed water on the clay mineral surfaces. Although it is difficult to check this, it is assumed that the permeability data reported here are comparable to the permeability of a water-saturated clay gouge, because a water-saturated clay gouge will also have such adsorbed water. An interesting point to be made here is that the coarser gouges, which exhibited higher permeabilities than the finer gouges (Fig. 6(a)), are also the clay-poor gouges and contain higher proportions of quartz microclasts. Thus although the impact of grain size on measured permeability is likely to be important, the effect of mineralogy should also be taken into account due to the preference of this structured water for clay minerals.

The calculations of hydraulic diffusivity also rely on a valid application of the compressibility data to the water- saturated gouge pore storage system. The compressibility of the gas-saturated gouge was measured over finite strain intervals, corresponding to confining pressure steps of typically $25 \mathrm{MPa}$ or more. During the first confining pressure cycle, increasing confining pressure led to both an elastic (recoverable) and a plastic (irrecoverable) component to the volumetric strain as demonstrated by the resulting permanent strain at the end of the pressure cycle (Fig. 3). Thus the calculated compressibility, related to the finite strain, will be significantly higher than the elastic compressibility. In elastic-plastic theory of soil mechanics based on experimental data (e.g. Wood, 1990), a clay or sand aggregate deforms elastically initially upon loading, but reaches a yield point beyond which plastic deformation occurs. If the load is totally removed somewhere beyond the yield point, elastic recovery occurs so that the remaining strain is the plastic component. Upon re-loading, the sample will deform elastically up to the previous peak stress state (which will act as the new yield point), and then plastically beyond this point. The yield point of the gouges was probably initially very low, but after confinement the new yield point will have been at a pressure $(P c-P p)$ of $180 \mathrm{MPa}$, because this was the peak pressure to which each gouge sample was subjected. Hence all the compressibilities calculated for the confining part of the first pressure cycle will result from both elastic and plastic components of strain, whereas those calculated for the deconfining part will be elastic compressibilities only. This explains why the compressibilities measured during deconfinement are approximately half an order-of-magnitude lower than during initial confinement - the difference being the plastic component of strain in the compressibility calculation. A check on the later behaviour was made by pressure cycling over three cycles (Fig. 5). The compressibility data 

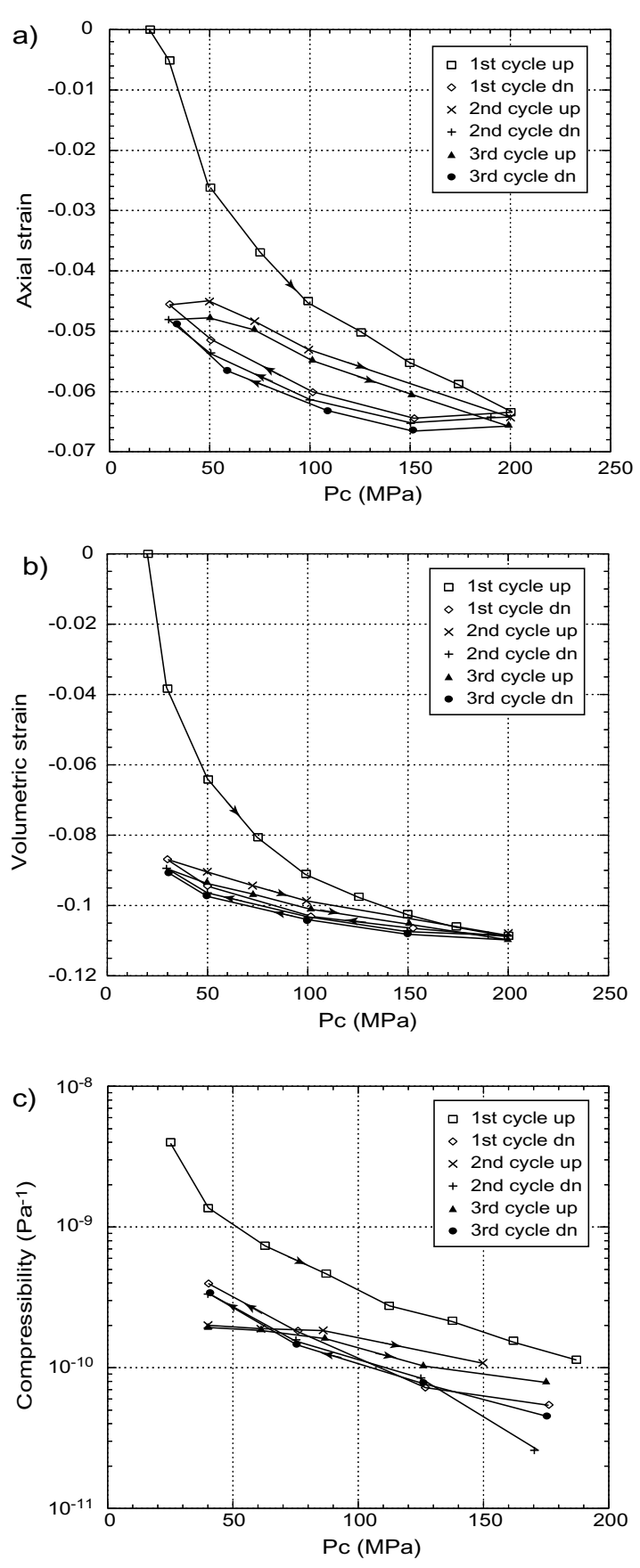

Fig. 5. Poroelastic data for foliated gouge sample F3xb. Each pressure cycle produced close to $100 \%$ recovery of strain except for the first cycle. Hence behaviour is elastic, after compaction to the first Pc peak. (a) Axial strain data. (b) Volumetric strain data. (c) Bulk framework compressibility data. Note the effect that hysteresis has on the first compressibility measurement at the start of a new increasing Pc or decreasing Pc path.

(Fig. 5(c)) were found to be consistent from cycle to cycle, and independent of whether the path was of increasing $P c$ or decreasing $P c$. This repeat behaviour indicates elasticity, but the fact that compressibility is still dependent upon pressure demonstrates that the sample behaviour is non-linearly elastic. This is important for the translation of the gouge 'bulk' or 'matrix' compressibility into the calculation of hydraulic diffusivity for the case of a water-saturated gouge, because such a calculation is valid only for poro-elastic behaviour.
Indeed, the oscillating pore pressure experiments used to determine storage capacity were performed under small mean effective stress changes in which elastic, infinitesimal strain was occurring. For the cases of measurements performed during the decreasing $P c$ part of the pressure cycle, compressibility measurements are elastic compressibilities, and are therefore directly applicable to the calculation of hydraulic diffusivity (Fig. 6(b)). For the measurements on the increasing $P c$ path in which a combined elastic-plastic compressibility has been used however, a compressibility value higher than the elastic matrix compressibility will have been used, resulted in underestimates of hydraulic diffusivity. Is it difficult to determine exactly the true elastic contributions to the compressibilities calculated in the experiments, so that a correction in the calculation of hydraulic diffusivies was not possible. However, the comparison between compressibilities during $P c$ increase in the first pressure cycle, and those from the decreasing $P c$ path and later pressure cycles, gives an impression of the impact of the plastic component on the first cycle increasing $P c$ compressibility data (Fig. 5(c)).

\subsection{The hydromechanical response of slip zone gouge during fluid pressurization}

The data presented in this paper show that the very fine gouge from a $10 \mathrm{~cm}$ wide principal displacement zone in the centre of the Median Tectonic Line fault core has a room temperature hydraulic diffusivity of around $1 \times 10^{-7}$ to $4 \times 10^{-7} \mathrm{~m}^{2} \mathrm{~s}^{-1}$ after compaction to $P c-P p$ values of $80 \mathrm{MPa}$ and above. The properties of surrounding gouges, even ones adjacent to this principal displacement zone such as sample $\mathrm{Ba}$, suggest much higher hydraulic diffusivities, typically $5 \times 10^{-6}$ to $5 \times 10^{-4} \mathrm{~m}^{2} \mathrm{~s}^{-1}$. This section considers the implications of such hydraulic diffusivity data for models of fluid-controlled slip processes, particularly thermal pressurization. During earthquake slip, frictional heating of the pore fluid will cause a combination of three possible endmember responses: thermal expansion of the fluid resulting in expansion of the pores, thermal expansion of the fluid resulting in drainage out of the heated zone, and pressurization of the fluid if trapped within the pores of the heated zone. If thermal pressurization of the fluid occurs, the consequent reduction in effective normal stress could result in dramatic slip weakening (Sibson, 1973). Measured elastic compressibility values suggest that pore compressibility will be less than the compressibility of water at room temperature $\left(\beta_{f}=4.277 \times 10^{-10} \mathrm{~Pa}^{-1}\right)$. Furthermore, fluid compressibility increases with temperature, so pores will certainly be less compressible than the water as it heats up. Poro-elastic expansion (the first of the three end-member responses) is therefore considered unlikely. The likelihood of thermal pressurization acting as a slip-weakening mechanism therefore balances on the relationship between the rate of frictional heating, and the rate at which a consequent fluid pressure pulse will be dissipated by fluid drainage from the heated zone. A first approximation is given by considering the undrained case. The decrease in effective normal stress on the fault can be calculated by considering the fluid pressure increase due to thermal expansion. For a thermal expansivity of water, $\alpha_{t}$, of $1.5 \times 10^{-3} \mathrm{~K}^{-1}$, the fractional change in water density $\left(\Delta \rho_{w} / \rho_{w}\right)$ due to a $30^{\circ} \mathrm{C}$ temperature rise, for example, will be 0.045 . The rise in fluid pressure of the 

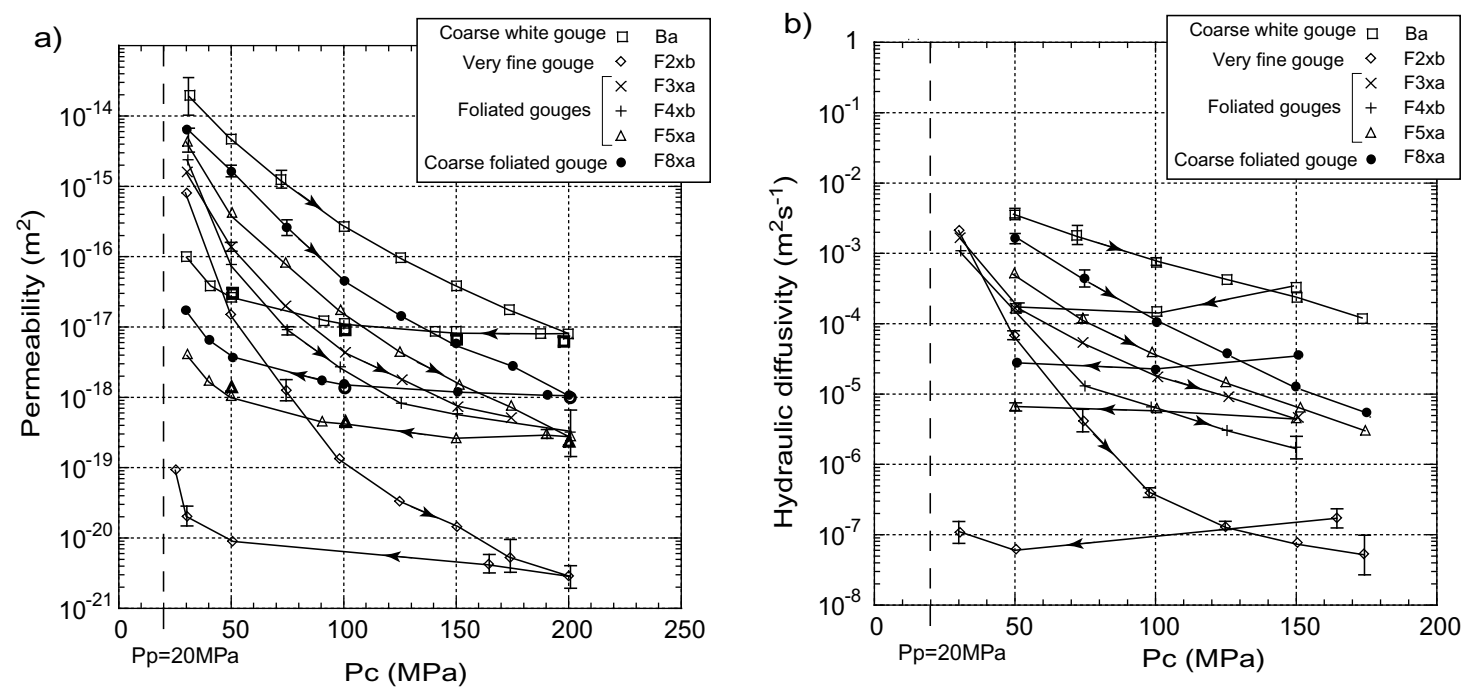

Fig. 6. Hydrodynamic properties of the fault gouges studied. (a) Permeability data, measured at a pore pressure of $20 \mathrm{MPa}$, except for the data are marked by bold open symbols which represent measurements at $30 \mathrm{MPa}$. Error bars were derived from standard deviations of repeated oscillation data. (b) Hydraulic diffusivity data derived using room temperature viscosity as discussed in the text. Error bars represent the added errors from permeability and from storage capacity measurements.

water, $\Delta P_{w}$ can be found as:

$$
\Delta P_{w}=\frac{\Delta \rho_{w}}{\rho_{w}} \cdot \frac{1}{\beta_{w}} .
$$

Assuming a compressibility of water of $4.3 \times 10^{-10} \mathrm{~Pa}^{-1}$ the fluid pressure rise and consequent drop in effective normal stress is then $106 \mathrm{MPa}$.

For the fluid drainage problem, a simple calculation of the rate of fluid pressure dissipation from the centre of a low-permeability zone (half - width $=x$ ) to both edges is done as follows. This is provided only as a brief illustration of the use of fault zone hydraulic property data, and the reader is referred to recent modelling work for more rigorous solutions incorporating the frictional heating aspects of the problem (e.g. Vardoulakis, 2001; Andrews, 2003) in addition to the references provided in the introduction. From Darcy's law, the rate of fluid flux through an area $\mathrm{A}$ is expressed in terms of fluid pressure excess $\left(\Delta P_{w}\right)$ as:

$$
\dot{q}=\frac{k A}{\eta} \frac{d \Delta P_{w}}{x}=D_{h} \beta_{c} A \frac{d \Delta P_{w}}{x} .
$$

The rate volume loss of fluid from the centre of the zone, in both directions, is $2 \dot{q}$. Given that the material around the very fine gouge slip zone of the Median Tectonic Line has much higher hydraulic diffusivity values, it is assumed here that this adjacent material will act in a drained manner. This is not necessarily the case, so the limits on thermal pressurization of the slip zone pore fluid here provide a conservative estimate for the conditions required for thermal pressurization. One condition on the occurrence of effective thermal pressurization is therefore that the hydraulic diffusion length be significantly smaller than the half-width of the low-permeability slip zone. The hydraulic diffusion length scale, or distance of propagation of a fluid pressure front $d_{h}$ from a heat source at time $t$, can be related to the hydraulic diffusivity as (Lachenbruch, 1980):

$$
d_{h}(t)=\sqrt{\left(4 D_{h} t\right)}
$$

suggesting that over a $10 \mathrm{~s}$ period a fluid pressure front will propagate approximately $2 \mathrm{~mm}$ in each direction from the source (using $D_{h}=1 \times 10^{-7} \mathrm{~m}^{2} \mathrm{~s}^{-1}$ for the very fine gouge slip zone). Given that the central slip zone is approximately $10 \mathrm{~cm}$ wide, although it does vary laterally along the outcrop examined, it is unlikely that the fluid pressure front will propagate beyond the low permeability slip zone during a rapid slip event.

The rate of pressure drop $\left(d P_{w} / d t\right)$ due to the fluid escape is:

$$
\frac{d P_{w}}{d t}=\frac{2 \dot{q}}{\beta_{f} n V}=\frac{2 D_{h} \beta_{c} A \Delta P}{\beta_{f} \times n V}
$$

where $n V$ is the pore volume in the central heated zone. If an approximation is used whereby the volume of the central slip zone (per unit length of fault) is considered to be that of the whole low-permeability zone, then $V=A x$ so that Eq. (6) can be simplified:

$$
\frac{d P_{w}}{d t}=\frac{2 D_{h} \beta_{c} \Delta P}{\beta_{f} n x^{2}} .
$$

The pore compressibility is thought to be sufficiently lower than the fluid compressibility (Subsection 5.1) that a second approximation can be made, that the storage capacity is close to that due only to the compressibility of the fluid, so that Eq. (2) can be modified:

$$
\beta_{c}=n \beta_{f}
$$

and by substituting Eq. (8) into Eq. (7), a simple determination of the rate of fluid pressure loss is given:

$$
\frac{d P_{w}}{d t}=\frac{2 D_{h} \Delta P}{x^{2}}
$$

The relationship in Eq. (9) is shown in Fig. 7(a), for the case of room temperature hydraulic conductivity (line 1 ). 

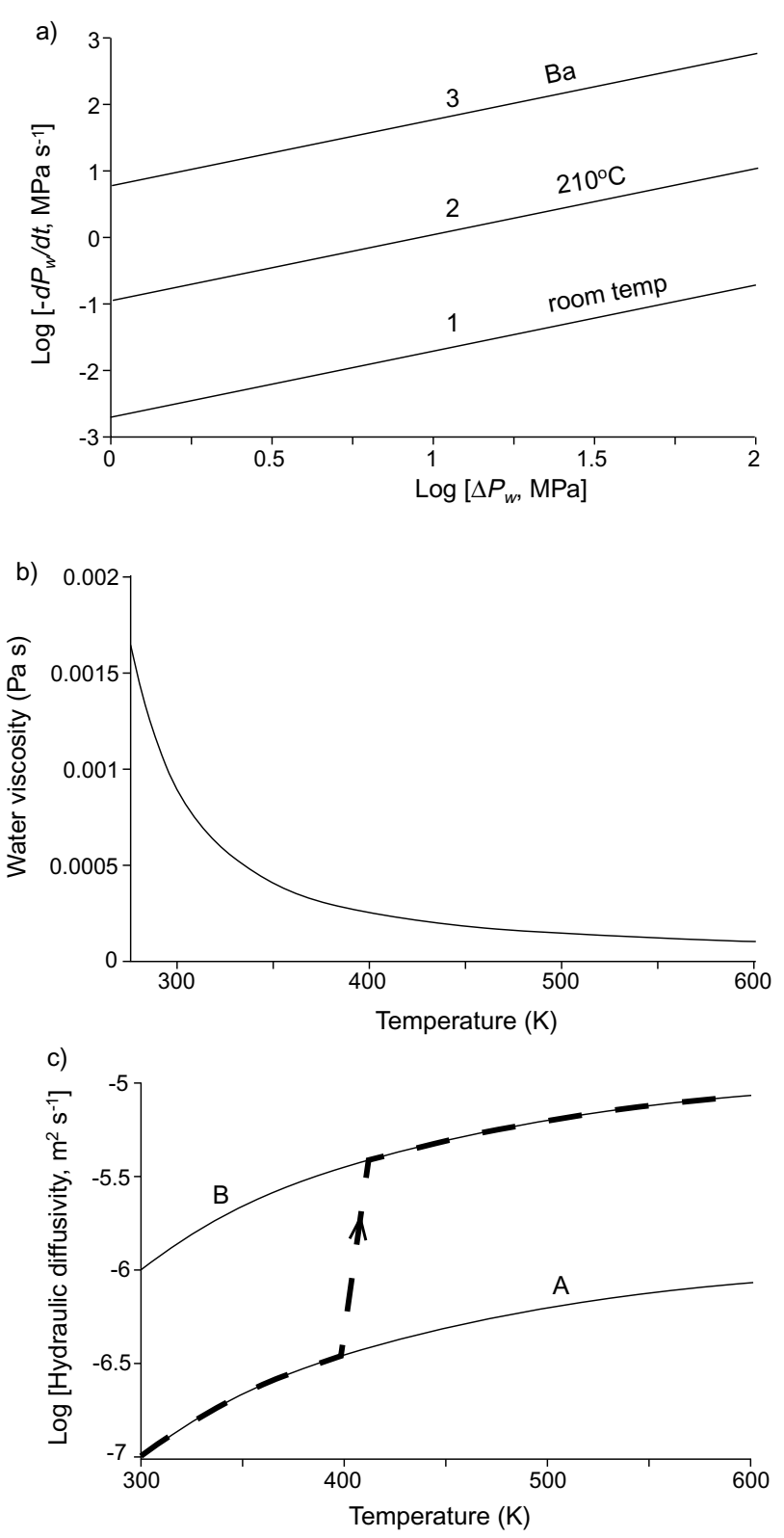

Fig. 7. The impact of temperature on gouge hydraulic diffusivity and rates of fluid pressure drop. (a) Fluid pressure drop rates vs. the magnitude of excess fluid pressure in the case of relatively incompressible pores, using Eq. (9), with $x=0.01 \mathrm{~m}$, for three different hydraulic diffusivity cases: 1 - room temperature case using data from principal displacement zone gouge sample $\mathrm{F} 2 \mathrm{xb}\left(D_{h}=1 \times 10^{-7} \mathrm{~m}^{2} \mathrm{~s}^{-1}\right) ; 2$ - case at $210^{\circ} \mathrm{C}$ for sample F2xb $\left(D_{h}=5.75 \times 10^{-6} \mathrm{~m}^{2} \mathrm{~s}^{-1}\right) ; 3$ - room temperature case for coarse gouge sample Ba $\left(D_{h}=3 \times 10^{-4} \mathrm{~m}^{2} \mathrm{~s}^{-1}\right)$. (b) The effect of temperature on water viscosity. (c) The impact of viscosity temperature-dependence on gouge hydraulic diffusivity for sample Fx $2 b$, extrapolating from the room temperature case (deconfining pathway data in Fig. 6(b)), (curve A), and one order of magnitude higher, supposing this to represent gouge permeability once the structured water on clay grain surfaces has been driven off (curve B). The dashed line represents a possible real dependence of hydraulic diffusivity on temperature, taking both of these effects into account.

\subsection{Likely hydrodynamic behaviour of slip zone gouge at elevated temperatures}

This section discusses the impact of two consequences of heating on the hydrodynamic properties of the gouge. Firstly, the increase in temperature of the pore water will decrease its viscosity (Fig. 7(b)), resulting in the hydraulic diffusivity in the slip zone being higher at higher temperatures. From the room temperature calculations of hydraulic diffusivity (Fig. 6(b)), the corresponding higher temperature hydraulic diffusivities can be calculated from known water viscosity values. Unlike the effect of temperature, fluid pressure does not alter viscosity much, and is not considered here. Figure 7(c) (curve A) shows the increase in hydraulic diffusivity with temperature due to this decrease in water viscosity. Secondly, the structured water present on the surface of the clay grains in the gouge below approximately $120^{\circ} \mathrm{C}$ contributes to the relatively low permeability of clay rich gouges. Above this temperature, the structured water films may be driven off. Although the effect of this on water permeability has never been monitored at such temperatures, comparison of gas permeability data for naturally dry clayrich gouges with water-saturated permeabilities suggests that permeability will increase by approximately 1 order of magnitude if the structured water layers are not present (Faulkner and Rutter, 2000). Removal of the structured water at $120^{\circ} \mathrm{C}$ would cause an increase in hydraulic diffusivity of one order of magnitude at this temperature (curve B, Fig. 7(c)).

The effect that these phenomena have on the dynamic slipweakening effect during an earthquake depends upon the temperatures to which the water-saturated gouge is heated. In the case of a low permeability slip zone, Mase and Smith (1987) showed that the temperature rise would never be more than $20-50^{\circ} \mathrm{C}$ because initial thermal pressurization would decrease effective normal stress sufficiently to dramatically lower the rate of frictional heating. In such a case, the sequence of processes frictional slip $\rightarrow$ heat generation $\rightarrow$ pore water pressurization $\rightarrow$ reduction in friction and rate of heating is occurring on the fault, and the frictional temperature pulse is self-arresting. The impact of temperature on fluid viscosity, and therefore hydraulic diffusivity and the feasibility of thermal pressurization, is likely to be due to the initial ambient temperature more than by temperature rise. Hence the depth must be taken into consideration in calculations of the fluid pressure dissipation. An example is shown on Fig. 7(a) (line 2) of fluid pressure dissipation rate at a temperature of $210^{\circ} \mathrm{C}$ (corresponding to a depth of $7 \mathrm{~km}$ at a temperature gradient of $30^{\circ} \mathrm{C} / \mathrm{km}$ ).

\subsection{Additional limitations provided by the constraints of fault zone structure}

The gouge samples studied in this work were cored parallel to foliation. Data in Wibberley and Shimamoto (2003) show that at $P c-P p=80 \mathrm{MPa}$ on the confining path, permeability perpendicular to foliation was more than one order of magnitude lower than permeability parallel to foliation. Similar anisotropy in permeability of clay gouges has been demonstrated in other works (e.g. Faulkner and Rutter, 1998). The estimates of gouge hydraulic diffusivity presented in this paper are therefore likely to be one order of magnitude higher than in situ hydraulic diffusivities perpendicular to the slip zone. The findings rely on propagation of slip only in the central slip zone gouge, which has sufficiently low permeability and hydraulic diffusivity for thermal pressurization to initiate. Outcrop observations of complex fault core zones (e.g. Wibberley and Shimamoto, 2003) suggest that ruptures can propagate obliquely or branch off a pre-existing slip plane in certain cases, and fault zone com- 
plexity must be taken into consideration. If such a lowpermeability zone is not laterally continuous, or the rupture plane propagates into another type of fault rock (such as at an asperity or point of interaction between a minor fault and the main slip plane), then fluid pressure may be released before effective pressurization can occur. A point where the slip plane propagates into coarser gouge or fractured cemented fault rocks in the wall rock to the principal displacement zone will experience higher fluid pressure dissipation rates. This is exemplified by line 3 in Fig. 7(a), using data on coarse gouge hydraulic diffusivity from sample $\mathrm{Ba}$. A final point is that the state of the gouge zone may change through geological time, leading to different hydromechanical deformation mechanisms being favoured. Reworking of a gouge at a shallower conditions to its original depth of generation may create a greater porosity, thereby leading to fluidization. Overprinting of textures suggesting different hydromechanical mechanisms has recently been identified in gouge from the Nojima fault (Otsuki et al., 2003) further underlining the importance of considering the deformation history of the gouge in understanding the hydromechanical behaviour of the fault.

\section{Summary}

This study investigates the laboratory fluid flow properties of fault gouges to find that:

1) Hydraulic diffusivity of the very fine clay gouge from the principal displacement zone of the MTL is around $1 \times$ $10^{-7} \mathrm{~m}^{2} \mathrm{~s}^{-1}$ if subjected to a peak $P c-P p$ of $180 \mathrm{MPa}$ at room temperature.

2) A fluid pressure pulse created by rapid frictional heating will remain trapped in the low-permeability slip zone, provided the gouge was initially at a pressure difference $P c-P p$ of at least several $10 \mathrm{~s}$ of $\mathrm{MPa}$.

3) The trapped fluid pressure pulse will not cause pore dilation, but instead the rising fluid pressure will lead to a decreasing effective normal stress, resulting in a lower shear strength.

4) This process of dynamic shear strength reduction during earthquake slip could ultimately be limited by propagation of the rupture front into a high-permeability adjacent fault rock, such as at an asperity or branch point, leading to high dissipation rates of the excess fluid pressure.

Acknowledgments. This work has been carried out during receipt of a JSPS fellowship under the guidance of Professor T. Shimamoto, who is most sincerely thanked for his encouragement The organisers and participants of the 'International Symposium on Slip and Flow Processes in and below the Seismogenic Regime' in Sendai, November 2001, are thanked for the opportunity to discuss this work. Tomochika Tokunaga and an anonymous reviewer are thanked for their helpful comments on the manuscript.

\section{References}

Andrews, D. J., A fault constitutive relation accounting for thermal pressurization of pore fluid, J. Geophys. Res., 2003 (in press).

Birch, F., Compressibility; Elastic constants, in Handbook of Physical Constants, edited by S. P. Clark, The Geological Society of America Memoir 97, 97-173, 1966.

Caine, J. S., J. P. Evans, and C. B. Forster, Fault zone architecture and permeability structure, Geology, 24, 1025-1028, 1996.

Chu, C. L., C. Y. Wang, and W. Lin, Permeability and frictional properties of San Andreas fault gouges, Geophys. Res. Lett., 8, 565-568, 1981.
Evans, J. P., C. B. Forster, and J. V. Goddard, Permeability of fault-related rocks, and implications for hydraulic structure of fault zones, Journal of Structural Geology, 19, 1393-1404, 1997.

Faulkner, D. R. and E. H. Rutter, The gas-permeability of clay-bearing fault gouge at $20^{\circ} \mathrm{C}$, in Faulting, fault sealing and fluid-flow in hydrocarbon reservoirs, edited by G. Jones, Q. Fischer, and R. J. Knipe. Geological Society Special Publication 147, 147-156, 1998.

Faulkner, D. R. and E. H. Rutter, Comparisons of water and argon permeability in natural clay-bearing fault gouge under high pressure at $20^{\circ} \mathrm{C}, \mathrm{J}$. Geophys. Res., 105, 16415-16426, 2000.

Fischer, G. J., The determination of permeability and storage capacity: pore pressure oscillation method, in Fault Mechanics and Transport Properties of Rocks, edited by B. Evans and T.-F. Wong, pp. 187-211, Academic Press, 1992.

Fischer, G. J. and M. S. Paterson, Measurement of permeability and storage capacity in rocks during deformation at high temperature and pressure, in Fault Mechanics and Transport Properties of Rocks, edited by B. Evans and T.-F. Wong, pp. 213-252, Academic Press, 1992.

Green, D. H. and H. F. Wang, Fluid pressure response to undrained compression in saturated sedimentary rock, Geophysics, 51, 948-956, 1986.

Hickman, S., R. Sibson, and R. Bruhn, Introduction to special section: Mechanical involvement of fluids in faulting, J. Geophys. Res., 100 12,831-12,840, 1995.

Ichikawa, K., Geohistory of the Median Tectonic Line of Southwest Japan, Memoir of the Geological Society of Japan, 18, 187-212, 1980.

Klinkenberg, L. J., The permeability of porous media to liquids and gases, Am. Petrol. Inst., Drilling and Production Practice, 2, 200-213, 1941.

Kobayashi, K. and 11 others, Distribution of fault rocks in the fracture zone of the Nojima Fault at a depth of $1140 \mathrm{~m}$ : Observations from the Hirabayashi NIED drill core, in The Nojima Fault Zone Probe, edited by N. Oshiman, T. Shimamoto, K. Takemura, and C. A. J. Wibberley, The Island Arc, 10, pp. 411-421, 2001

Kranz, R. L., J. S. Saltzman, and J. D. Blacic, Hydraulic diffusivity measurements on laboratory rock samples using an oscillating pore pressure method, International Journal of Rock Mechanics and Mining Sciences and Geomechanics Abstracts, 27, 345-352, 1990.

Lachenbruch, A., Frictional heating, fluid pressure, and the resistance to fault motion, J. Geophys. Res., 85, 6097-6112, 1980.

Lockner, D., H. Naka, H. Tanaka, H. Ito, and R. Ikeda, Permeability and strength of the Nojima core samples from the Nojima fault of the 1995 Kobe earthquake, in Proceedings of the international workshop on the Nojima fault core and borehole data analysis, edited by H. Ito, K Fujimoto, H. Tanaka, and D. Lockner, USGS Open File Report 00-129, 147-152, 2000.

Mase, C. W. and L. Smith, Effects of frictional heating on the thermal, hydrological, and mechanical response of a fault, J. Geophys. Res., 92 , 6249-6272, 1987

Miller, S. A., Earthquake scaling and the strength of seismogenic faults, Geophys. Res. Lett., 29, GL014181, 2002.

Mizoguchi, K., T. Hirose, and T. Shimamoto, Permeability structure of the Nojima fault at Funaki, Hokudan-cho, Japan, Gekkanchikyu-gougai (Earth Monthly), 31, 58-65, 2000 (in Japanese).

Morrow, C. A., L. Q. Shi, and J. D. Byerlee, Permeability and strength of San Andreas gouge under high pressure, Geophys. Res. Lett., 8, 325-329, 1981.

Morrow, C. A., L. Q. Shi, and J. D. Byerlee, Permeability of fault gouge under confining pressure and shear stress, J. Geophys. Res., 89, 3193 $3200,1984$.

Morrow, C. A., Z. Bo-Chong, and J. D. Byerlee, Effective pressure law for permeability of Westerly Granite under cyclic loading, J. Geophys. Res., 91, 3870-3876, 1986.

Ohtani, T., H. Tanaka, K. Fujimoto, T. Higuchi, N. Tomida, and H. Ito, Internal structure of the Nojima Fault zone from the Hirabayashi GSJ drill core, in The Nojima Fault Zone Probe, edited by N. Oshiman, T. Shimamoto, K. Takemura, and C. A. J. Wibberley, The Island Arc, 10, pp. 392-400, 2001.

Otsuki, K., N. Monzawa, and T. Nagase, Fluidization and melting of fault gouge during seismic slip: Identification in the Nojima fault zone and implications for focal earthquake mechanisms, J. Geophys. Res., 2003 (in press).

Scholz, C. H. and S. H. Hickman, Hysteresis in the closure of a nominally flat crack, J. Geophys. Res., 88, 6501-6504, 1983.

Seront, B., T.-F. Wong, J. S. Caine, C. B. Forster, R. L. Bruhn, and J. T. Fredrich, Laboratory characterization of hydrodynamical properties of a seismogenic normal fault system, Journal of Structural Geology, 20 , 
865-881, 1998.

Sibson, R. H., Interactions between temperature and pore-fluid pressure during earthquake faulting and a mechanism for partial or total stress relief, Nature, 243, 66-68, 1973

Tadokoro, K., K. Nishigami, M. Ando, N. Hirata, T. Iidaka, Y. Hashida, K Shimakaki, S. Ohmi, Y. Kano, M. Koizumi, S. Matsuo, and H. Wada, Seismicity changes related to a water injection experiment in the Nojima Fault zone, in The Nojima Fault Zone Probe, edited by N. Oshiman, T. Shimamoto, K. Takemura and C. A. J. Wibberley, The Island Arc, 10, pp. 235-243, 2001.

Takagi, H., Implications of mylonitic microstructures for the geotectonic evolution of the Median Tectonic Line, central Japan, Journal of Structural Geology, 8, 3-14, 1986.

Vardoulakis, I., Thermo-poro-mechanical analysis of rapid fault deformation, in Powders and Grains, Proceedings of the 4th International Confer- ence on Micromechanics of Granular Media, Sendai, Japan, 2001.

Wibberley, C. A. J. and T. Shimamoto, Internal structure and permeability of major strike-slip fault zones: the Median Tectonic Line in Mie Prefecture, Southwest Japan, Journal of Structural Geology, 25, 59-78, 2003.

Wood, D. M., Soil behaviour and critical state soil mechanics, 462 pp., Cambridge University Press, Cambridge, 1990.

Zhang, S. and S. F. Cox, Enhancement of fluid permeability during shear deformation of a synthetic mud, Journal of Structural Geology, 22, 13851393, 2000.

Zhu, W. and T.-F. Wong, The transition from brittle faulting to cataclastic flow: permeability evolution, J. Geophys. Res., 102, 3027-3041, 1997.

C. A. J. Wibberley (e-mail: cwibber@ip.media.kyoto-u.ac.jp) 